NBER WORKING PAPER SERIES

\title{
INHERITANCES AND THE DISTRIBUTION OF WEALTH OR WHATEVER HAPPENED TO THE GREAT INHERITANCE BOOM? RESULTS FROM THE SCF AND PSID
}

\author{
Edward N. Wolff \\ Maury Gittleman \\ Working Paper 16840 \\ http://www.nber.org/papers/w16840 \\ NATIONAL BUREAU OF ECONOMIC RESEARCH \\ 1050 Massachusetts Avenue \\ Cambridge, MA 02138 \\ February 2011
}

An earlier version of this paper was presented at the BCL/ECB Joint Conference on Household Finance and Consumption, Luxembourg, October 25-26, 2010. We would like to thank our discussant, Helen Connolly, for her very helpful comments. We would also like to gratefully acknowledge the financial support of the Russell Sage Foundation for this project. The views expressed here are those of the authors and do not necessarily reflect the views or policies of the Bureau of Labor Statistics, any other agency of the U.S. Department of Labor, or the National Bureau of Economic Research.

NBER working papers are circulated for discussion and comment purposes. They have not been peerreviewed or been subject to the review by the NBER Board of Directors that accompanies official NBER publications.

(C) 2011 by Edward N. Wolff and Maury Gittleman. All rights reserved. Short sections of text, not to exceed two paragraphs, may be quoted without explicit permission provided that full credit, including (c) notice, is given to the source. 
Inheritances and the Distribution of Wealth or Whatever Happened to the Great Inheritance

Boom? Results from the SCF and PSID

Edward N. Wolff and Maury Gittleman

NBER Working Paper No. 16840

February 2011

JEL No. D31,J1

\begin{abstract}
$\underline{\text { ABSTRACT }}$
Using data from both the Survey of Consumer Finances (SCF) and the Panel Study of Income Dynamics (PSID), we found that on average over the period from 1984 to 2007, about one fifth of American households at a given point of time received a wealth transfer and these accounted for about a quarter of their net worth. Over the lifetime, about 30 percent of households could expect to receive a wealth transfer and these would account for close to 40 percent of their net worth near time of death. However, there is little evidence of an inheritance "boom." In fact, from 1989 to 2007, the share of households in the SCF reporting a wealth transfer fell by 2.5 percentage points. The average value of inheritances received among all households did increase but at a slow pace, by 10 percent, but wealth transfers as a proportion of current net worth fell sharply over this period, from 29 to 19 percent. We also found, somewhat surprisingly, that inheritances and other wealth transfers tend to be equalizing in terms of the distribution of household wealth. Indeed, the addition of wealth transfers to other sources of household wealth has had a sizeable effect on reducing the inequality of wealth.
\end{abstract}

\author{
Edward N. Wolff \\ Department of Economics \\ New York University \\ 19 W. 4th Street, 6th Floor \\ New York, NY 10012 \\ and NBER \\ edward.wolff@nyu.edu \\ Maury Gittleman \\ Bureau of Labor Statistics \\ 2 Massachusetts Avenue NE, Rm 4130 \\ Washington, DC 20212 \\ gittleman_m@bls.gov
}




\section{Introduction}

Previous estimates indicate that inheritances and gifts have accounted for between 20 and 50 percent of total household wealth accumulation in the U.S. Wealth transfers are also an important source of both business and home ownership. The conventional wisdom is that inheritances contribute to the overall inequality of household wealth. Moreover, it is commonly believed that inheritances impede intergenerational wealth mobility and play an important role in accounting for the intergenerational transmission of economic and social privilege.

Along these lines, inheritances have been implicated in a variety of "sins." It is commonly believed that an increase in the share of household wealth emanating from inheritances and a rise in the inequality of bequests will lead to a rise in wealth inequality. Likewise an increase in the proportion of household wealth attributable to inheritance and an increase in the inequality of bequests will generally lead to reduced wealth mobility.

In this regard, inheritances are seen as an important linkage in whether inequality today begets more inequality in the future. It is thought that rising wealth inequality today, coupled with an increasing share of inheritances in total wealth and rising bequest inequality, will lead to greater wealth inequality in the future. Such a process may result in a surge of wealth inequality in the coming decades. Moreover, this process may become self-perpetuating over time.

Furthermore, on the theoretical front, several papers have developed models to show why inheritances increase wealth inequality and serve as a major factor in explaining why wealth inequality is so much higher than income inequality. For example, the theoretical and simulation work of Oulton (1976) and Laitner (1992) indicate the impossibility of reconciling the two distributions without also assuming an unequal distribution of bequests.

The main focus of the paper is to examine the effects of inheritances and other wealth transfers on overall wealth inequality. The results reported below are surprising, unexpected and even counter-intuitive. We find that wealth transfers actually act as a factor that decreases wealth inequality rather than increasing it. Though we do not have 
hard empirical evidence on whether inheritances inhibit or spur intergenerational wealth mobility, we infer that wealth transfers are likely to raise the degree of wealth mobility across the generations.

A second issue addressed in the paper is whether inheritances grew or declined in importance between the mid-1980s and the mid-2000s. As we shall discuss below, a couple of commentators on the subject have suggested that the U.S. is poised to receive a huge intergenerational transfer of wealth. We do not find much evidence that the value of inheritances rose over the years from 1984 to 2007. Indeed, if anything, inheritances and other wealth transfers as a share of household net worth fell over this period.

A third important concern is whether the inequality of bequests has increased or fallen over time. This is also an important issue since the effects of inheritances on overall wealth inequality will depend on both the size of the bequests as well as on the degree of inequality in the inheritances themselves. One might expect that the wellknown rise in family income inequality that has been occurring in the U.S. since the late 1970s has led to a rise in the inequality of inheritances. However, here, too the evidence suggests otherwise, and, indeed, if anything there might have been a slight decline in the inequality of wealth transfers between 1984 and 2007.

Another important dimension is the well-being of the elderly. One important component in retirement adequacy is the accumulation of financial wealth. As individuals enter prime inheritance age, ages 50 to 60 , there has typically been a surge in average wealth holdings of this age group. This added wealth may make a vital difference in whether the elderly will be able to maintain living standards after retirement.

Many believe that both reduced wealth inequality and increased wealth mobility should be important public policy goals. As a consequence, the results of the paper may also lead us to rethink public policy, particularly with regard to the structure of the estate tax. The estate tax actually disappeared in the year 2010 but returned starting in the year 2011. ${ }^{1}$ Estimating and analyzing the magnitude of inheritances, particularly its trend in recent years, might inform Congress when it considers overhauling the estate tax and, in particular, how to structure the tax schedule.

\footnotetext{
${ }^{1}$ Under current law, the exemption on the estate tax was raised from its 2009 level, \$3,500,000, to $\$ 5,000,000$ and the top marginal tax rate lowered from its 2009 level of 45 percent down to 35 percent.
} 
Previous calculations from the Federal Reserve Board's Survey of Consumer Finances (SCF) indicate that the importance of gifts and inheritances as a source of household wealth accumulation declined between 1989 and 1998. As shown in Wolff (2002, 2003), the present value of wealth transfers (gifts and inheritances) as a share of current net worth plummeted from 30 to 19 percent over this period.

This paper will analyze more recent data from the SCF to determine whether inheritances have continued to fall in importance or whether the trend has reversed itself. Calculations will be performed from 1989 through the year 2007 on the basis of the SCF. We will also perform similar calculations on the basis of the Panel Study of Income Dynamics (PSID) from 1984 through 2007. As we shall see, the results are remarkably similar.

There is some reason to think that the trend has reversed because the current generation of elderly is now the richest in history (see Wolff, 2010). Moreover, the babyboom generation has now reached the prime inheritance age group of 50 to 59 (see Wolff, 1999 and 2003). For both reasons, the baby-boomers may be the first generation to inherit a considerable amount of money both in terms of the percentage of families inheriting as well as the amount inherited. Indeed, Avery and Rendall (1993) almost 20 years ago predicted that an inheritance boom would occur for baby boomers over the decade of the 2000s. More recently, Schervish and Havens (1999) predicted that over the 55-year period from 1998 to 2052, a minimum of \$41 trillion (in 1998 dollars) would pass from the older generation to the younger one.

The paper will thus investigate three main questions. First, how much, if at all, do inheritances and other wealth transfers contribute to overall wealth inequality? Second, have inheritances and other wealth transfers become more important over time? Third, has the inequality of wealth transfers risen over time?

Moreover, the paper will also determine for which groups, if any, inheritances and gifts have become more important over time and for which less important. Groups will be defined by race, education, age, income class, and wealth class. In addition, we will investigate the type of wealth transfer (inheritance, gift, trust fund, or other), the source of the wealth transfer (parent, grandparent, other relative, or friend), and the nature of the gift transfer (money, family business, real estate, etc.) on the basis of the SCF data. 
The next section of the paper (Section 2) provides a description of the SCF. Section 3 reviews the literature on the effects of inheritances on wealth accumulation and wealth inequality. Section 4 delves into inheritance and gift patterns in the U.S. over the period 1989-2007 on the basis of the SCF. In Section 5, a similar analysis is performed using the PSID. The last section (Section 6) presents concluding remarks.

\section{Data Sources and Methods: The Survey of Consumer Finances}

The first data sources for this study are the 1989, 1992, 1995, 1998, 2001, 2004, and 2007 Survey of Consumer Finances (SCF) conducted by the Federal Reserve Board. Each survey consists of a core representative sample combined with a high-income supplement. The supplement is drawn from the Internal Revenue Service's Statistics of Income data file. The high income supplement was selected as a list sample from statistical records (the Individual Tax File) derived from tax data by the Statistics of Income Division of the Internal Revenue Service (SOI). This second sample was designed to disproportionately select families that were likely to be relatively wealthy (see, for example, Kennickell, 2001, for a more extended discussion of the design of the list sample in the 2001 SCF). The advantage of the high-income supplement is that it provides a much fuller sample of high income and therefore potentially very wealthy families than a representative sample like the PSID.

The wealth concept used here is marketable wealth (or net worth), which is defined as the current value of all marketable or fungible assets less the current value of debts. Net worth is thus the difference in value between total assets and total liabilities or debt. Total assets are defined as the sum of: (1) the gross value of owner-occupied housing; (2) other real estate owned by the household; (3) cash and demand deposits; (4) time and savings deposits, certificates of deposit, and money market accounts; (5) government bonds, corporate bonds, foreign bonds, and other financial securities; (6) the cash surrender value of life insurance plans; (7) the cash surrender value of pension plans, including IRAs, Keogh, and 401(k) plans; (8) corporate stock and mutual funds; (9) net equity in unincorporated businesses; and (10) equity in trust funds. Total liabilities are the sum of: (1) mortgage debt, (2) consumer debt, and (3) other debt. 
This measure reflects wealth as a store of value and therefore a source of potential consumption. We believe that this is the concept that best reflects the level of well-being associated with a family's holdings. Thus, only assets that can be readily converted to cash (that is, "fungible" ones) are included. As a result, consumer durables such as automobiles, televisions, furniture, household appliances, and the like are excluded here, since these items are not easily marketed or their resale value typically far understates the value of their consumption services to the household.

The other notable exclusion is the value of future social security benefits the family may receive upon retirement (usually referred to as "social security wealth"), as well as the value of retirement benefits from private Defined Benefit pension plans ("pension wealth"). Even though these funds are a source of future income to families, they are not in their direct control and cannot be marketed. Therefore, they would not form part of marketable wealth. However, social security and pension wealth do enter into the determination of lifetime resources available to families, since they are an important source of income and therefore of consumption when individuals retire from the labor force. The estimation of these two forms of wealth from the SCF is beyond the scope of the current paper. ${ }^{2}$

The advantage of the SCF is that it provides detailed information not only on holdings of assets and liabilities by individual households but also on bequests and gifts received. Households are asked to record both the amount of the transfer received and the year of receipt. In addition, they are asked to indicate for selected asset holdings (real estate and businesses) whether the original source of the holding was from an inheritance or gift. This information will allow us to estimate the proportion of current wealth holdings that derives from transfers. It will also enable us to determine whether wealth transfers are, on net, equalizing or disequalizing with respect to current wealth holdings. ${ }^{3}$

\section{Literature Review on Inheritances}

\footnotetext{
${ }^{2}$ The inclusion of both social security and pension wealth in the definition of household wealth would result in a considerably more equal distribution of (augmented) wealth. See, for example, Wolff (1987).

${ }^{3}$ Unfortunately, it is not possible to simulate what the distribution of wealth would have been in the complete absence of gifts and inheritances. This simulation depends on the elasticity of substitution between transfers and (active) savings for different income, wealth, and demographic groups.
} 
Survey evidence on the importance of bequests is fairly consistent. Projector and Weiss (1966), using the 1963 Survey of Financial Characteristics of Consumers, reported that only 17 percent of families had received any inheritance. This compares with a figure of 18 percent, reported by Morgan, David, Cohen, and Brazer (1962). The Projector and Weiss study also found that only 5 percent of households had received a "substantial" proportion of their wealth from inheritance. However, this latter proportion did rise with household wealth, with 34 percent of families with net worth exceeding half a million dollars indicating a substantial bequest. Barlow, Brazer, and Morgan (1966) found from a 1964 Brookings study on the affluent, covering families with income of $\$ 10,000$ or more, that only 7 percent of the sample mentioned gifts and inheritance alone as the source of most of their present assets. They estimated that about one seventh of the total wealth of this group came from inheritance.

Menchik and David (1983) used probate records of men who died in Wisconsin between 1947 and 1978 to obtain an estimate of \$20,000 (in 1967 dollars) for the mean bequest of all decedents in their sample. This figure includes not only intergenerational transfers but interspousal and other transfers as well. David and Menchik (1982) estimated that the average interspousal transfer was $\$ 15,800$, with about one half of all individuals dying while still married. Moreover, they computed that about 60 percent of all non-interspousal bequests went to children. Putting these figures together, they obtained a rough estimate that the average intergenerational bequest among decedents was $\$ 7,500$ in 1967 dollars, which amounted to less than one fifth of average household wealth in 1967 and about 10 percent of the average household wealth of families with a head 65 or over in age.

Hurd and Mundaca (1989) analyzed data from both the 1964 Survey on the Economic Behavior of the Affluent and the 1983 Survey of Consumer Finances on the importance of gifts and inheritances in individual wealth holdings. ${ }^{4}$ Both surveys asked questions of the respondents about whether they had received gifts and inheritances and how much these transfers were worth. They found from the 1964 data that only 12

\footnotetext{
${ }^{4}$ Information on inheritances was available in some of the early releases of the 1983 SCF file but is deleted from the current public use sample of that file. It is for this reason that we are unable to use the 1983 SCF in the current study.
} 
percent of households in the top 10 percent of the income distribution reported that more than half their wealth came from gifts or inheritances. The corresponding figure from the 1983 data was only 9 percent. They concluded that intergenerational transfers were not an important source of wealth, even for rich families. However, Gale and Scholz (1994), using the 1983 Survey of Consumer Finances, estimated that at least 51 percent of household wealth was accounted for by inheritances and other "intentional" wealth transfers. Brown and Weisbenner (2004), using the 1998 SCF, estimated that 19 percent of households that year received some kind of wealth transfers (this is very close to our own estimate) and that one fifth to one fourth of aggregate household wealth was traceable to wealth transfers, depending on the interest rate used to capitalize past inheritances.

Laitner and Sonnega (2010) provide some recent evidence on this subject on the basis of a different data source, the 1992-2008 Health and Retirement Survey (HRS). The HRS is a panel survey that began in 1992 with a sample of respondents aged 51 to 61 . It has an extensive battery of questions about inheritances, trusts, and gifts received. The HRS uses a combination of retrospective questions on past wealth transfers as well waveto-wave questions on receipts received over the current period. Questions on bequest motives are also included. The authors find that 30 to 40 percent of households eventually receive an inheritance. This figure is a little higher than our estimate of around 30 percent (see Section 4). They also surmise that inheritances reflect a mixture of intentional and accidental bequests, with the latter twice as prevalent.

A similar type of analysis was conducted on French data by Kessler and Masson (1979) (also, see Kessler and Masson, 1989). In a 1975 survey of 2,000 French families, the respondent was asked whether the family had received any significant inheritance (above $\$ 4,000$ ) or gifts (above $\$ 2,000$ ). Of all the households in the sample, 36 percent reported that they had already received some inheritance. Of the total wealth of the population, Kessler and Masson estimated that 35 percent originated from inheritances or gifts. Among those who had reported receiving an intergenerational transfer (who were about two and a half times richer than the average household), the corresponding proportion was 40 percent. Klevmarken (2001) computed that 34.4 percent of Swedish households reported receiving a gift or inheritance in the 1998 Swedish HUS wealth 
survey. Using a three percent capitalization of inheritances and gifts (see below), he calculated that 19.0 percent of the wealth of Swedish households in 1998 originated in wealth transfers.

Generally speaking, direct survey evidence and econometric tests on household survey data (or probate records) have so far shown mixed results on the importance of bequests in household wealth accumulation. However, on the basis of the studies reviewed above, one might guess that about one fourth of household wealth emanates from inheritances and other forms of wealth transfers.

\section{Empirical Findings from the SCF, 1989-2007}

In this part of the paper, the SCF is used to investigate trends in inheritances. The method of data collection is based on recall. Respondents are asked to indicate whether they have received any inheritances, gifts, or other types of wealth transfers such as trust funds in the past, the value of the transfer, and the date at which it was received.

Questions on inheritances and gifts are asked in two different ways. First, there are several questions on what we call "general wealth transfers." These questions presumably refer to any type of gift or inheritance. Second, there are specific questions on inheritances and gifts of real estate and businesses. These are asked in the sections of the questionnaire which deal specifically with the value of homes, other properties, and businesses. In principle the questions on general wealth transfers should also capture the specific transfers indicated in the questions on real estate and businesses. Indeed, as one of the experts on the Survey of Consumer Finances indicated in an email, every effort was made during the editing of the SCF file to make sure that the general wealth transfer questions were consistent with the specific wealth transfer information. However, in our data analysis, we did find a few discrepancies between the two sets of question. To be on the conservative side, we therefore included the value of the specific wealth transfers only in the case when no general wealth transfer was reported.

The recall or recollection method is likely to have serious under-reporting problems, as suggested in the previous section, and estimates of inheritances reported below are very likely to be biased downward. However, it is difficult to ascertain whether 
there is a systematic bias in under-reporting by wealth class, by income class, or by demographic characteristics of the respondent.

On the basis of both the reported value of wealth transfers and the dates of the transfers, we compute the present value of all inheritances as of the survey year which were received up to the time of the survey by accumulating them at a real interest rate of 3.0 percent. $^{5}$ The value of inheritances is then converted to 2007 dollars. ${ }^{6}$

There is a debate about how past inheritances should be valued relative to current wealth. In particular, should the interest or capital gains received on past inheritances be counted as part of inheritances or as part of savings? The procedure used here is essentially a compromise. A normal rate of return on assets received from wealth transfers is assigned and this part of the return is counted in the inheritance portion of current wealth. ${ }^{7}$ Returns on inherited assets above this normal rate are implicitly treated as part of savings.

It should be noted at the outset that there appears to be a lot of sample variation from year to year. This is to be expected since inheritances and other wealth transfers are received by a small fraction of the population and their distribution is very skewed (as we shall see below). We are particularly interested in whether there are any notable time trends and we will point this out in the ensuing discussion.

\subsection{Trends in Inheritances, 1989-2007}

Table1 tabulates the responses to the general wealth transfer questions and the questions on specific receipts of real property and businesses. In 1998, for example, 20.3 percent responded “yes” to the questions on general wealth transfers, 3.1 percent

\footnotetext{
${ }^{5}$ Technically, the date of receipt is rounded off to the nearest fifth year in the Public Use version of the SCF, so that some error is introduced into the calculations. There is also no date of receipt provided for the category "other gifts and inheritances." Again, to be on the conservative side, we assume the wealth transfer in that case was received in the year of the survey.

${ }^{6}$ We trimmed the sample slightly by excluding all inheritances over $\$ 50,000,000$. In the 2004 SCF, there was one inheritance from a trust fund recorded at a value of $\$ 300,000,000$, which resulted in a present value in 2007 dollars of $\$ 18.483$ billion. This was excluded from the sample. However, also in the 2004 SCF, there was another inheritance recorded at $\$ 50,000,000$ from a trust fund, which we kept in the sample.

${ }^{7}$ According to our calculations, the average real rate of return on the average household wealth portfolio between 1989 and 2007 was 3.15 percent. We use a discount factor of 3 percent in our calculations. See Wolff, Zacharias, and Masterson (2009) for details.
} 
indicated receiving their own home as a gift or inheritance, 3.2 percent said "yes” for other real estate, 0.4 percent said "yes" for their own business, and 6.6 percent for either real estate or a business. ${ }^{8}$ All told, 20.4 percent of households indicated receiving some type of wealth transfer (line 5), compared to 20.3 percent for the general wealth transfer questions, for a discrepancy of 0.1 percentage points (line 6). This difference has remained quite small over the seven survey years, except for 1989, when the difference amounted to 0.4 percentage points.

Some general statistics are provided in the next two tables. Table 2 shows a breakdown of wealth transfers by type of transfer. Depending on the year, between 80 and 90 percent of households who received some type of wealth transfer received an inheritance. About 75 to 85 percent received only an inheritance. Among households receiving a transfer in 1998, 80 percent of the value of these transfers came from inheritances, 11 percent from gifts, and 9 percent from trusts. The importance of gifts appears to have risen over time from 1989 to 2007 while that of trusts has declined. There is no noticeable time trend for inheritances. ${ }^{9}$

In 1998, 64 percent of all wealth transfers came from parents, 23 percent from grandparents, 10 percent from other relatives, and 3 percent from friends and other sources (see Table 3). The contribution from parents alone rose from 1989 to 1998, from 56 to 64 percent of the total value of wealth transfers, and then increased to 76 percent in 2007 and that from parents and grandparents together increased from 74 percent in 1989 to 90 percent in 2007, while the share from other relatives, friends, and other sources slipped.

As shown in Table 4, 21.1 percent of all households in the 2007 SCF reported receiving a wealth transfer on or before that date. The average figure over the seven years from 1989 to 2007 was 20.9 percent. This latter figure is comparable to those from previous U.S. surveys but lower than the corresponding figures from French and Swedish household surveys. The 2007 U.S. figure represents a decline from 23.5 percent in 1989.

\footnotetext{
${ }^{8}$ We often focus on years 1989, 1998, and 2007 since the first and last are the end points of the period under investigation and 1998 is the exact midpoint.

${ }^{9}$ The year 2004 is particularly anomalous, where the share from trusts was 32 percent (and the share from inheritances was down to 63 percent). This reflected one very large transfer from a trust fund in that year.
} 
The change is also statistically significant. According to the seven SCF surveys, the fraction of households receiving a wealth transfer declined from 23.1 percent in 1989 to a low point of 17.8 percent in 2001, but then rose to 21.0 percent in 2007. The results suggest that over the full 18-year period, there was a moderate drop in the share of households receiving an inheritance.

There is also significant variation in the proportion of households receiving a wealth transfer by income, wealth, and demographic class. As expected, the share of recipients rises very strongly with income and wealth level. On average over the seven years, 38 percent of households in the highest income bracket (\$250,000 or more) reported a wealth transfer, compared to only 15 percent in the lowest income bracket (less than \$15,000); and 45 percent of households in the highest wealth bracket ( $\$ 1,000,000$ or more) received a transfer, ${ }^{10}$ compared to 9 percent in the lowest wealth bracket (less than $\$ 25,000$ ).

The proportion of non-Hispanic white households reporting a wealth transfer was on average more than twice as great as the share of non-Hispanic African-Americans (25 versus 10 percent). Only 5.5 percent of Hispanic households, on average, reported a wealth transfer, while the figure was higher, 12 percent, for Asian and other races.

As expected, the likelihood of receiving a wealth transfer also rises with age. On average, the share of households under age 35 receiving a transfer was 12 percent, compared to 30 percent of those in age bracket 65-74. However, the fraction of recipients in age group 75 was slightly lower, at 29 percent. This pattern reflects both life-cycle effects (the parents of older persons are more likely to have died than those of younger persons), as well as cohort effects (parents of those persons 75 and over were more likely to be poorer than parents of younger people). The likelihood of inheriting or receiving a gift also rises with education -- from 14 percent for those with less than four years of high school to 29 percent for college graduates. This result is consistent with the patterns found by income and wealth class.

Almost all income, wealth, and demographic groups saw a moderate decline in the share of transfer recipients between 1989 and 2001, in conformity with the overall

\footnotetext{
10 The figure was slightly lower for the top one percent of wealth holders at 44 percent.
} 
decline in the proportion of households reporting a wealth transfer. However, there were some exceptions to this pattern. There was a precipitous drop in the share of recipients among the highest income group, from 48 to 36 percent, and for the top one percent of the wealth distribution, from 57 to 44 percent. Even though the standard errors are large for these groups, the changes are statistically significant. From 2001 to 2007, the reverse generally held with the share reporting a transfer rising almost across the board. A huge gain, in particular, occurred for the lowest income class (from 10 to 17 percent).

However, the share of households in the top wealth percentile reporting a wealth transfer remained virtually unchanged.

The share of white households receiving a transfer declined by 6.3 percentage points from 1989 to 2001, whereas the share of African-American households showed a smaller decline (2.2 percentage points). The change is statistically significant for whites but not for black households. The share of Asians who reported a transfer plummeted from 17 percent in 1989 to 10 percent in 2001, a change that is statistically significant even with the small sample size for this group, while that for Hispanics fell from 5.8 to 3.0 percent (though not statistically significant). This trend may be a reflection of the large immigration of both Asians and Hispanics to the U.S. during the 1990s (and the relative low wealth holdings of their parents). In contrast, the transfer rate picked up among all groups from 2001 to 2007, with the largest gains reported by whites (4.3 percentage points) and Asians (4.9 percentage points). Changes in the share of households reporting a transfer by age class and educational group followed the general trends from 1989 to 2001 and from 2001 to 2007. If the 75 and over age group is considered to represent the "end of lifetime" age group, it appears that about 29 percent of households on average will receive some type of wealth transfer over their lifetime.

Tables 5 and 6 show the present value of wealth transfers received for recipients only. In 1998, the mean present value of wealth transfers among recipients was $\$ 323,500$ and the median was $\$ 71,000$ (both in 2007 dollars). It is of note that the large difference in the mean and median value of transfers is of the same order of magnitude as that between mean and median household wealth and indicates considerable skewness in the distribution of wealth transfers (as we shall see below). 
We also find similar patterns as in Table 4. Both the mean and median value of wealth transfers tends to rise with household income, and there is a huge jump for the highest income class. In 1998, the mean present value of wealth transfers for the top income class ( $\$ 250,000$ or more) was more than 14 times as great as for the lowest (under $\$ 15,000)$, and the median transfer was more than seven times as large. Wealth transfers increase monotonically with wealth, with again a big jump for the top wealth class. The mean present value of wealth transfers for the highest wealth class $(\$ 1,000,000$ or more) was more than 24 times as great as for the lowest (under \$25,000) in 1998, and the median transfer was more than 17 times as large. Indeed, the ratio was 65 for mean values and 26 for median values between the top one percent of wealth holders and the bottom wealth class.

Wealth transfers are also higher for non-Hispanic whites than for non-Hispanic African-Americans. In 1998, the ratio of means among recipients between the two groups was 1.52 and the ratio of medians was 1.26. Asians ranked first in terms of mean wealth transfers and Hispanics last in 1998, while Hispanics ranked first in terms of median transfers, followed by Asians, whites, and then blacks.

Not surprisingly, both the mean and median values of wealth transfers rise with age. In 1998, the mean transfer for households age 75 and over was 5 times as great as that for the youngest age group (under 35), while the median transfer was almost four times as great. The value of wealth transfers received also rises with the educational level of the households and is particularly high for college graduates. In 1998, the mean transfer of the latter was 3.6 times as great as that for households with less than a high school education, and the median value was 2.3 times as great.

The results of Table 5 also indicate a sharp decline in the mean (present) value of wealth transfers between 1989 and 1998 among recipients - over 16 percent. The median value showed a moderate increase -- by 7.3 percent. However, from 1998 to 2007 the situation reversed and the mean value of wealth transfers among recipients climbed by 47 percent and the median value by 26 percent. ${ }^{11}$ Over the full 18 -year period, the mean value rose strongly, by 23 percent, while the median value gained 36 percent (both of

\footnotetext{
${ }^{11}$ The 2004 figure for mean transfers is much higher than the 2007 figure, a reflection of the very large wealth transfer from a trust fund in 2004 noted above.
} 
these changes are statistically significant at the one percent level). Both the mean value and the median value of transfers generally display a rising trend over time, despite some year-to-year fluctuations.

The decline in the mean value of wealth transfers from 1989 to 1998 was especially marked among the upper four income classes. Some of the lower income classes actually experienced a rise in the value of their wealth transfers. From 1998 to 2007, all income classes experienced a rise in the mean value of wealth transfers with the exception of the top income class. Over the full 1989 to 2007 period, all income classes except the top one registered gains in mean wealth transfers, with the lowest income class showing a 92 percent increase, while the top income class suffered a decline of 23 percent.

The pattern is different by wealth class. From 1989 to 1998, the mean value of wealth transfers generally increased among the lower wealth classes but declined among the upper wealth classes with the notable exception of the top one percent, which experienced a 77 percent gain. From 1998 to 2007, in contrast, all wealth classes enjoyed increases in the mean value of wealth transfers, with the exception of the second and third. Over the full 18 years, the bottom two wealth classes as well as the top $(\$ 1,000,000$ or more) saw their mean transfers go down whereas the four in the middle saw gains. The top one percent saw their transfers surge by 143 percent.

Mean wealth transfers declined slightly among whites but increased by 30 percent among black households and by 23 percent among Asian-Americans from 1989 to 1998. Among Hispanics, they rose between 1992 and $1998 .^{12}$ Median transfers increased among all racial and ethnic groups. From 1998 to 2007, both mean and median transfers were up among all four groups except Hispanics which saw a decline in median transfers. Over the full 1989-2007 period, both mean and median wealth transfers rose among all four groups except mean transfers among Hispanics, though at almost double the rate for black households than white households and at approximately three times the rate among Asians as among whites. Mean transfers fell among Hispanic households from 1989 to 2007 but climbed from 1992 to 2007.

\footnotetext{
12 The 1989 mean value of \$1,695,100 for Hispanic households appears to be an outlier, based on the small sample size of this group (only 13 cases).
} 
Mean wealth transfers fell for the two youngest age groups and age group 65 to 74 from 1989 to 1998 but rose for the other age classes. Median values likewise decreased for the bottom two age groups and for age group 65 to 74 but increased for the others. In contrast, from 1998 to 2007, both mean and median values of wealth transfers were almost universally up across age groups with the notable exception of mean transfers among the oldest one. All told, mean transfers fell among the youngest age groups and age group 65 to 74 from 1989 to 2007 and rose among the other age groups, whereas median transfers were up among all age groups except the youngest one.

From 1989 to 1998, mean transfers were down sharply among all educational groups except high school graduates but from 1998 to 2007 the pattern was exactly reversed. Over the whole 1989 to 2007 period, mean and median transfers showed gains among all groups except the least educated, among whom they showed slight declines.

Table 7 puts together trends in mean wealth transfers among recipients with trends in the share of households receiving transfers to yield mean inheritances among all households within group. We now see a much greater spread in the value of wealth transfers received than among recipients only. This pattern reflects the positive correlation between the share of households receiving a wealth transfer and the average value of that wealth transfer. In 1998, the ratio of mean transfers received between the top and bottom income class was 40 to 1, compared to 14 to 1 among recipients only. In the same year, the ratio between the top wealth class of $\$ 1,000,000$ or more and the bottom wealth class was 109!, compared to 24 among recipients only. The ratio in mean transfers in 1998 between white and black households was 3.3, in comparison to1.5 among recipients only. Likewise, the spread between the oldest and youngest age classes in mean transfers was 12.3 compared to 5.1 among recipients, and that between college graduates and the least educated was 7.3 among all households and only 3.6 among recipients.

Overall mean transfers were down by 28 percent from 1989 to 1998 and then up by 54 percent from 1998 to 2007, for a net gain of 10 percent. This compares to a 23 percent increase for mean transfers among recipients only. Mean transfers generally declined over the earlier period within income, wealth, and demographic groups and increased in the later period. Over the full period, average transfers generally fell by 
income class (down by 37 percent for the top income class, for example) with the notable exception of the bottom one which experienced a 104 percent increase. Transfers were almost universally down by wealth class, again with the notable exception of the top one percent who saw their average transfers climb by 93 percent.

Average transfers rose among white, black, and Asian households but much more for the latter two than for whites. Hispanics suffered a decline from 1989 to 2007 but saw large gains from 1992 to 2007. Mean transfers increased among middle age households (particularly age group 55 to 64 which saw a gain of 88 percent) and among the oldest group but fell by 24 percent for the youngest group and by 32 percent for age group 65 to 74. There was little change in average transfers by educational group except for the least educated which saw a 31 percent drop.

Table 8 shows the present value of wealth transfers received as a percent of the current net worth of households. This ratio provides a rough gauge of the importance of inheritances, gifts, and other wealth transfers in household wealth accumulation. In 1998, the figure was 19.4 percent among all households. The unweighted average over the whole 1989 to 2007 period was 23.2 percent. These figures are comparable to previous estimates for U.S households and for Swedish households (19 percent in 1998) but lower than the figure of 35 percent for French households in 1975. However, since net worth rose during the 1990s in the U.S. and the mean value of wealth transfers dipped, this proportion also fell rather sharply over the years from 1989 to 1998 from 29 to 19 percent. From 1998 to 2007, the mean value of wealth transfers rose by 52 percent while mean net worth rose about the same degree, so that this ratio remained unchanged at 19 percent. Over the full 18-year period, wealth transfers as a share of net worth fell rather sharply, from 29 to 19 percent (the difference is significant at the one percent level). It appears that the importance of inheritances as a source of household wealth accumulation fell off over these years.

Another surprising result is that while both the percentage of households receiving a wealth transfer and the value of those transfers rise almost monotonically with income and wealth class, wealth transfers as a share of household net worth tends to decline with both income and wealth. In 1998, the present value of wealth transfers amounted to 45 percent of the net worth of the lowest income class and only 17 percent 
for the highest income class. Likewise, the present value of these transfers accounted for 46 percent of the wealth of the second lowest wealth class $(\$ 25,000-\$ 49,999)$, compared to 17 percent for both the top wealth class of $\$ 1,000,000$ or more and the top one percent. ${ }^{13}$ The rationale is that while the dollar value of wealth transfers is greater for wealthier groups, small gifts and bequests mean more to poorer families. This relation will produce some rather counter-intuitive results regarding the effects of inheritances on wealth inequality - namely that inheritances will be seen as an equalizing factor on wealth inequality -- as will be seen below.

Indeed, the inverse relation between wealth transfers as a share of current net worth and both income and wealth level appears to have become more pronounced over the 1989-2007 period. While the ratio fell from 55 to 43 percent for the lowest income class, it plummeted from 30 to 13 percent for the top income class. Likewise, while the ratio fell from 48 to 31 percent for the second wealth class, it dipped by almost half for the top wealth class, from 24 to 16 percent, and for the top one percent, from 23 to 15 percent.

It is also of note that wealth transfers amounted to a greater proportion of the current net worth of African-American than of white households in 1998 -- 32 percent versus 19 percent. Wealth transfers also made up a much smaller share of the wealth holdings of Hispanics and Asian-Americans than of whites in 1998. While this share generally declined over time among white households, there was no clear time trend in this ratio for blacks or Hispanics. Among Asians, this share increased somewhat from 1989 to 2007.

Though the total value of wealth transfers tends to rise with the age of the householder, wealth transfers as a share of current wealth tend to have a U-shaped relation. The share is high for young households, because of their low savings, and for older households, because of the high absolute value of such transfers. It is low for middle-age households, because of their relatively small amount of inheritances and large level of savings. This pattern remains fairly robust over time. In 1998, the ratio of wealth

\footnotetext{
${ }^{13}$ For the bottom wealth class, the mean present value of wealth transfers was $\$ 4,700$, while the mean net worth of this group was $-\$ 53$.
} 
transfers to net worth was relatively constant across educational groups. However, there was considerable year-to-year fluctuation in this pattern.

Another cut is provided in Table 9. Here we isolate the wealth transfers received in only the five and ten years preceding the survey year. ${ }^{14}$ These figures are likely to be more reliable than those on wealth transfers received over the whole lifetime (at least up to current age), since recall is better for more recent events than those further away in time. Line 6 of Panels A and B provides the final estimate on all wealth transfers received. Here, despite some bouncing around from year to year, there is some indication of a slight upward trend in the share of households reporting a wealth transfer, from 7.7 percent in 1989 to 8.4 percent in 2007 over the preceding five years and from 12.1 to 13.3 percent over the preceding ten years. There was an upward trend in mean values as well, from $\$ 123,900$ to $\$ 165,300$ over the preceding five years and from $\$ 135,100$ to $\$ 213,200$ over the preceding ten years.

\subsection{Trends in the Inequality of Wealth Transfers, 1989 to 2007}

Another topic of interest in this paper is whether the inequality of wealth transfers has increased over time. As shown in Table 10, the Gini coefficient for wealth transfers received among all households was incredibly high in 1998, 0.96. Even limiting the sample to recipients lowers the Gini coefficient to only 0.80 . This compares to a Gini coefficient for net worth in 1998 of 0.82 (see Wolff, 2010). There is a U-shaped pattern of wealth transfer inequality with respect to income level, with Gini coefficients for recipients only falling from 0.73 for the bottom income class to 0.66 for the middle one and then rising steeply to 0.90 for the top income class. Inequality of wealth transfers is much higher among white households (a Gini value of 0.81) than African-American ones (0.73) or Hispanics (0.53). There is also a U-shaped pattern of wealth transfer inequality with respect to age, with Gini coefficients falling from 0.79 for the youngest group to 0.75 for age groups $45-54$ and 55-64 and once again increasing sharply to 0.87 for the oldest group. More educated households also have a higher degree of wealth transfer inequality than less educated ones, particularly the least educated group.

\footnotetext{
${ }^{14}$ As noted above, the SCF combines wealth transfers received into five year intervals preceding the survey year.
} 
Patterns are quite similar in 2007. The main exception is that the inequality of wealth transfers tends to fall off with age, though the relationship is a bit irregular. In 1989, patterns are similar to those for 1998, except that wealth transfer inequality tends to rise with income and, among racial and ethnic groups, it is higher among Hispanics than among whites or African-Americans.

Overall, there is no clear indication that the inequality of inheritances, gifts, and other wealth transfers rose or declined between 1989 and 2007. The Gini coefficient of wealth transfers among all households was virtually unchanged over the period, while that among recipients only fell slightly, by 0.01 points. The Gini coefficient of wealth transfers among recipients only rose by 0.03 points for the lowest income class, fell by 0.06 points for the middle income group, but changed little for the other income groups. Transfer inequality was relatively unchanged among white and black households, though it did fall off steeply among Hispanics (though, as noted above, the figure for 1989 is based on a very small sample size and is likely to be unreliable).

Gini coefficients show a steep increase for the youngest age group of 0.05 points and for age group $45-54$ of 0.08 points but slip by 0.07 points for age group 65-74. They also fall among less educated households, particularly among high school graduates (a 0.05 point drop) but rise among the least educated group by 0.03 points. All in all, changes in the inequality of wealth transfers are quite mixed across income and demographic groups.

Another indicator of the inequality of wealth transfers is its correlation with wealth and income. We first show the correlation of wealth transfers (WT) and net worth excluding wealth transfers (NWX). This correlation, as we shall discuss below, is uniformly negative. This means that less wealthy households tend to receive greater transfers relative to the size of their wealth holdings than richer ones. The results seem to indicate that the correlation has become less negative over time, suggesting that it has become less pro-poor over the period. However, as we shall see in the next section, this relationship tends to bounce around a lot over time. In contrast, as might be evident from Table 7, there is generally a positive relation between wealth transfers and household income. However, as shown in Table 11, the correlation is quite low - 0.074 in 2007. Moreover, this correlation has come down over time, from 0.122 in 1989. 
As noted in the introduction, it is not possible to simulate the effects of eliminating wealth transfers on the size distribution of wealth. Such an exercise would require a full behavioral model of household savings, and, in particular, a fully estimated response function of savings to the receipt of inheritances and other wealth transfers. ${ }^{15}$ For such an analysis we would have to estimate this response function for different income and wealth classes and for different demographic groups.

Instead, a decomposition analysis based on the coefficient of variation is used to assess the effects of inheritances and other wealth transfers on the inequality of wealth. ${ }^{16}$ As derived in Wolff (1987), for any variable $X=X_{1}+X_{2}$,

$$
\mathrm{CV}^{2}(\mathrm{X})=\mathrm{p}_{1}{ }^{2} \mathrm{CV}^{2}\left(\mathrm{X}_{1}\right)+\mathrm{p}_{2}{ }^{2} \mathrm{CV}^{2}\left(\mathrm{X}_{2}\right)+2 \mathrm{CC}\left(\mathrm{X}_{1}, \mathrm{X}_{2}\right)
$$

where $\mathrm{CV}$ is the coefficient of variation (the ratio of the standard deviation to the mean), CC is the coefficient of covariation, defined as the ratio of the covariance to $\mathrm{X}^{2}$, $\mathrm{p}_{1}=$ $\mathrm{X}_{1} / \mathrm{X}$, and $\mathrm{p}_{2}=\mathrm{X}_{2} / \mathrm{X}$.

Results are shown in Table 11. It is first of note that the correlation between wealth transfers (WT) and current wealth holdings excluding transfers (NWX) is negative in all seven years -- that is, households with lower wealth holdings exclusive of wealth transfers receive higher wealth transfers. The value of the correlation coefficient varies over time, from a range of -0.30 in 1989 to -0.71 in 1992. For 1998, the value is -0.47 . For 2001 and 2007, the correlation is quite low in absolute value -- -.011 and -0.17, respectively - but for 2004 it is at its highest point, -0.80 .

As a result, in all seven years, the (negative) correlation between WT and NWX serves to reduce overall wealth inequality (the third lines in Panels A and B). However, the distribution of wealth transfers is much more skewed than the distribution of NWX. This is true for all seven years. For 1998, for example, the coefficient of variation of NWX is 9.1, compared to a value of 22.5 for WT. From this effect, the addition of wealth

\footnotetext{
${ }^{15}$ Actually, the model would be even more complicated for two reasons. First, household savings would also respond to anticipated inheritances, which would be even harder to measure. Second, in a world without transfers, the savings behavior of those leaving inheritances would also be different.

${ }^{16}$ Because of the large number of negative and zero net worth values, it is not possible to use a decomposition of the Theil coefficient.
} 
transfers to other wealth holdings serves to increase overall wealth inequality (line 1 of Panels A and B).

The net effect of inheritances and other wealth transfers on overall wealth inequality depends on the relative magnitude of the two effects. For all seven years except 2001 and 2007, the covariation effect outweighs the direct effect of adding wealth transfers to other wealth holdings and actually results in a sizeable reduction in wealth inequality. For 1998, the coefficient of variation of NWX is 9.1, while that of NW is 6.6. Thus, adding wealth transfers to NWX results in a 28 percent reduction of wealth inequality. The coefficient of variation also declines by 28 percent in 1989, by 51 percent in 1992, and by 46 percent in 1995. In 2001, the percentage decline is 15 percent, in 2004, 54 percent, and, in 2007, 18 percent. From this standpoint, the net effect of wealth transfers is to equalize the overall distribution of wealth.

\section{Results from the PSID}

In this section, we turn to an alternative data source, the PSID, to continue our examination of trends and patterns in inheritances and the relationship between inheritances and the distribution of wealth. It is useful to look at results from an alternative source of data to see whether they are consistent with those from the SCF. As we shall see, the PSID results are remarkable consistent with the SCF results reported in Section 4.

The PSID is a longitudinal survey of a representative sample of U.S. individuals and the families in which they reside, which was begun with a sample of approximately 4,800 families in 1968. Data were collected annually through 1997 and since that time, data have been collected biennially. As the PSID was originally based on two subsamples, one of which oversampled the low-income population, the use of weights enables analysts to make estimates that are representative of the U. S. population.

The PSID collects two types of information useful for this study, each offering a different perspective on inheritances. Since 1988, the PSID has obtained information on the amount that families have inherited in the previous calendar year. Thus, it is possible to examine trends over the past two decades in the level of inheritances, as well as to 
assess differences in inheritances by family group, where groups are defined by income class, race, age and education.

In addition, the PSID has collected data on wealth via special supplements carried out in 1984, 1989, 1994, 1999, 2001, 2003, 2005, 2007 and 2009. During these same years, questions have also been asked about inheritances, in part to aid in understanding where the family's assets came from. In 1984, respondents were asked if they or anyone in the family had ever received an inheritance of money or property. In later years, a retrospective period was imposed which was equal to the number of years since the most recent wealth supplement, so that in 1989, 1994 and 1999 it was five years, while in 2001, 2003, 2005, 2007 and 2009 it was two years. In addition, the question was revised to ask about inheritances of money or property worth $\$ 10,000$ or more.

The combination of inheritance and wealth data in the same year enables analyses similar to those in the preceding section using the SCF, particularly for 1984, when a complete history of inheritances is available. Thus, it will be of great interest to see whether the surprising findings about the contribution of inheritances to overall wealth inequality for the SCF are also true for the 1984 PSID.

For the purposes of the present study, the PSID has several key advantages over other datasets. First, because of the rapport that PSID interviewers have developed with respondent families over time, the rate of item non-response in the wealth questions is relatively low. Second, because the PSID oversamples the low-income population, the number of African-American families is larger than in the SCF, and the PSID is, thus, likely to provide better information on inheritances received by African-American families. Third, much of the information collected about inheritances has a short retrospective period, thus one subject to less recall error.

There are, however, three important limitations of the PSID data. First, the PSID does not oversample the extremely rich. Second, wealth components in the PSID are grouped into only seven broad categories, many fewer than in the SCF. Net worth is measured in the PSID by adding the net values of the home, other real estate, the farm or business, vehicles, stocks, bank accounts and "other savings” and then subtracting nonmortgage debt. Third, the longitudinal nature of the PSID and the imposition of 
retrospective periods mean that the sample structure is different from that of the SCF in which a fresh cross-section is drawn for each survey and the household is asked its entire history of inheritances. This limitation of the PSID imposes some difficulties for gauging trends over time in inheritances and their relationship to overall wealth inequality.

\section{$\underline{5.1 \text { Patterns of Inheritances }}$}

Beginning in 1988, the PSID asked families whether they have inherited money or property in the previous year as part of its series of income questions. ${ }^{17}$ Table 12 shows the proportion of families who received inheritances, along with the mean and median values of these inheritances among the recipients in 2007 dollars. Data are available for 15 survey years, but these years span nearly two decades because of the switch to biennial data collection after 1997. It is clear that in any given year an inheritance is relatively rare, involving no more than 1 to 2 percent of families. Perhaps of more interest is whether there is any tendency for the rate of recipiency to grow. There does not seem to be, as the share inheriting dips from around 2 percent in the late 1980early 1990s to 1.0 percent in 1994 before recovering to its previous levels.

What about in terms of the levels of inheritances? The average amount inherited fluctuates a great deal, in part due to sampling variability, but there is no evidence of a strong upward trend. Less movement is shown among the medians, but, here, too, one would be hard pressed to say that there is a significant upward trend.

Table 13 does, however, display obvious differences across income and demographic groups in the rate and amount of inheritance receipt over the 1987 to 2006 period. Pooling the data from 15 survey years, one finds that, on average, 1.8 percent of the families inherited in a given year. This percentage is less than half that for the lowest income group (under \$15,000 in \$1998) and almost double that for the top income group ( $\$ 250,000$ or more). Consistent with past research on race differences in inheritances (for example, Menchik and Jianakoplos, 1997; Avery and Rendall, 1997; and Gittleman and

17 In 1968, the first year of the PSID, respondents were asked: "Did you get any other money in the last year -- like a big settlement from an insurance company, an inheritance, or anything?” Similar questions have been included since that time. Unfortunately, using the information elicited from these questions is problematic until 1988 for two reasons: the amounts are bracketed until 1984 and it is not until 1988 that a follow-up question seeks to disentangle inheritances from insurance settlements and the like. 
Wolff, 2004), the likelihood of families headed by African Americans to inherit was much lower than average, only 0.5 percent, and one quarter that of white families. ${ }^{18}$

The prime age group in which to inherit is 55-64 years of age (2.9 percent). Indeed, the overall pattern is U-shaped, rising from 1.1 percent for the youngest age group to 2.9 percent for the 55-64 age group and then dropping down to 1.5 percent for the oldest group. The results on inheritance recipiency rates by age group are consistent with the simulation results of Greenwood and Wolff (1992) and Wolff (1999). The age pattern of inheritances primarily reflects the life expectancies of the parental generation.

The likelihood of inheriting is strongly increasing in the education level of the head of the family, rising from 0.9 percent for those with heads who have not graduated high school to 2.5 percent for college graduates. The results on education are consistent with those of recipiency rates by income class discussed above.

The pattern of results for the amount inherited, both in the terms of means and medians, is very similar to that for the likelihood of having received an inheritance. The amount received by recipient families is monotonically increasing in both income and education. White families received inheritances that were well more than double those of African American families. Finally, those with heads in the 55-64 age class inherited the most when measured by the means, though those in the 65-74 age group inherited the most when medians are used. Like the proportion of families inheriting, there is a Ushaped pattern for both mean and median values of inheritances among recipients, rising from $\$ 24,400$ to $\$ 67,300$ in the case of mean values and then falling off to $\$ 44,400$.

The last column of Table 13 shows the mean value of inheritances received among all households in each group. Here, the patterns of receipt are even sharper than in the second column. Mean inheritances among all households increase very sharply with income (there is a 24-fold difference between the top and bottom income classes). There is now an almost 10 -fold ratio in mean values between whites and blacks. The age profile for mean inheritances now rises more sharply among all households than among recipients only for age class under 35 to a peak at ages 55-64 and then falls more steeply

\footnotetext{
${ }^{18}$ White families actually include all those which are not classified as African-American. While it would be desirable to have a finer breakdown by race/ethnicity, the small sample size and changes over time in the racial and ethnic categories in the PSID questionnaires do not allow for this.
} 
after that. Mean inheritances received among all households now rises more sharply with educational level than among recipients only.

We now turn to inheritance information collected concurrently with the wealth information. ${ }^{19}$ In 1984, the PSID first asked whether the respondent or anyone in the family living there ever inherited any money or property. Those who said yes were then asked how many inheritances they received, and, for up to two inheritances, the year of the inheritance and the amount the inheritance was worth at the time it was received. ${ }^{20}$ As noted above, beginning in 1989, there was a retrospective period (the time since the last wealth supplement) and a minimum threshold of $\$ 10,000$ when the respondent was first asked about inheritances. In 1989, as in 1984, information on the value and year was collected for two inheritances, but for the remaining years this information was collected for three inheritances.

As in the case of the SCF data, on the basis of the amount of the inheritance received and the date of receipt, we compute the present value of the inheritance as of the survey year by accumulating them at a real interest rate of 3.0 percent. The value of inheritances is then converted to 2007 dollars. Table 14 presents some overall statistics on the receipt and amount of inheritances in the PSID from 1984 to 2007. In the 1984 survey, the one in which the approach is most comparable to that used in the SCF because the retrospective period is not of fixed length and there is no minimum threshold, nearly one-fifth of the families reported that an inheritance had been received. Among these families, the mean value of such a transfer was $\$ 193,500$ while the median was $\$ 42,900$. These figures compare to a mean value of $\$ 413,100$ on the basis of the SCF data averaged over all survey years from 1989 to 2007 and an average median value of $\$ 85,600$. The PSID values are about half those drawn from the SCF data. One possible reason for the discrepancy is that, as discussed in Section 2, the SCF data have a highincome supplement so that more very wealthy households are represented in the SCF

\footnotetext{
19 To our knowledge, these data have not been used extensively, though see Laitner and Ohlsson (2001) for an important exception.

${ }^{20}$ Only a small number of families indicated the receipt of more than two inheritances. It should be noted that, in contrast to the SCF data, only inheritances are included here as wealth transfers. In the SCF data, we included both inheritances and gifts as wealth transfers.
} 
samples. A second potential reason is that the PSID data are from 1984 whereas the SCF figures are from later years.

For the three surveys where the retrospective period is five years, the rate of inheritance is roughly 6 percent in both 1989 and 1994 and then it jumps to nearly 8 percent in 1999. At the same time, the amount of the inheritances among recipients shows a downward trend, with the mean falling from $\$ 144.8$ thousand to $\$ 99.0$ thousand between 1989 and 1999 and the median falling from \$54.2 thousand to \$40.6 thousand over the same time span. These patterns can be compared to those for the SCF in 1989, 1995 and 1998 when the retrospective period is limited to 5 years and a minimum transfer threshold of $\$ 10,000$ is put in place, shown in Table 19. In the SCF, recipiency of a general wealth transfer declines from 5.3 percent to 3.4 percent between 1989 and 1995, but then does rise to 6.0 percent in 1998. In terms of amounts, the mean shows something of an inverted U-shape when the present value of wealth transfers for recipients only is examined. It rises from \$250.5 thousand in 1989 to \$354.7 thousand in 1995, before falling to $\$ 181.0$ thousand in 1998. These much higher values reflect the fact that the SCF better captures the top of the wealth distribution than does the PSID. The median falls from $\$ 86.9$ thousand in 1989 to $\$ 44.0$ thousand in 1995, before recovering somewhat to $\$ 64.2$ thousand. Reassuringly, the cross-survey differences in medians are smaller than those for the means.

Table 15 shows how the incidence of inheritance varies by income, wealth and demographic class, as measured in the PSID. In terms of ever having received an inheritance, the complete retrospective data from the 1984 survey indicates that this proportion increases with family income, except for at the highest income level, where the sample sizes are small and thus likely to be more affected by sampling variability. A similar phenomenon is evident when families are arrayed by wealth class. Consistent with past research, African-American families are much less likely to have received an inheritance than white families. Not surprisingly, the likelihood of ever having inherited increases with age. The figure for age group 75 and over from the PSID in 1984, 32.2 percent, is somewhat higher than the corresponding figure from the SCF for that age group averaged over all SCF survey years from 1989 to 2007, 29.1 percent. Finally, the 
proportion of families that has ever received an inheritance is strongly increasing with education level.

The statistics for the other survey years, which have either five- or two-year retrospective periods, naturally have much lower levels of receipt, but the patterns by category tend to be broadly similar: Receipt rises with income, wealth, and education, even more steeply than for 1984 , which is attributable in part to the fact that the $\$ 10,000$ threshold reduces the likelihood of inheriting more at the lower income, wealth, and education classes than at the higher ones. This reasoning would lead one to expect the ratio of receipt among white families to that among African-American families to be higher with a threshold than for the 1984 data, which has no threshold. This holds true for surveys with a five-year retrospective period, but the ratio is not that different with a twoyear retrospective period than in 1984. For age class, however, it is not surprising that the patterns differ when a retrospective period is imposed; there is an inverted U-shape, with the likelihood of receipt peaking between 45 and 64 . This pattern is similar to that shown in Table 13.

Once again the results in Table 15 from 1989, 1994 and 1999 can be compared with those from 1989, 1995 and 1998 from the SCF in Table 19. Though there are differences in slopes, both tables are similar in that recipiency rates tend to rise with income, wealth and education. The patterns by age are also broadly similar. Race differences in recipiency rates, however, tend to be greater in the PSID than the SCF. It is conceivable that, here, the PSID provides the more accurate view, since it oversamples the low-income population and thus has a larger sample of African-American families. ${ }^{21}$

In Tables 16 and 17, we consider the values of the inheritances and how they vary by income, wealth and demographic class, as measured in the PSID. Again, assessing the results for 1984 separately from those for the other survey years, the mean present value of inheritances by family income class has a surprising pattern in that it is not close to being monotonically increasing in income. While it is easy to dismiss the small size of the mean for the top income class, since there are only three families in this group, the

\footnotetext{
${ }^{21}$ Another potential reason for the difference in results between the two surveys is that the racial categories are defined differently. In the PSID data, the category "whites," as noted above in footnote 18, are defined as those who are not African-Americans. In the SCF data, four racial categories are used: (1) non-Hispanic whites; (2) non-Hispanic African-Americans; (3) Hispanics; and (4) Asians and other races.
} 
other ups and downs are harder to explain. However, the median present value of inheritances by family income class conforms more closely to expectations, a result which suggests that the mean is unduly influenced by outliers.

Perhaps because wealth and education are better indicators of the permanent level of financial resources than annual income, the results for these categories are also more in line with expectations. Both the mean and median present values of inheritances tend to rise with wealth levels, and these values are strongly monotonic in education levels. Mean inheritances are much higher for whites than for African Americans, and, while the gap is narrower at the median, it is still evident. Mean inheritances follow the expected pattern of increasing with age, but the tendency is somewhat harder to discern at the median.

Because some oddities were evident for 1984, with its complete retrospective period, it is perhaps no surprise that the patterns are not that transparent for the other years, when the smaller time window for inheritances implies small sample sizes for many of the sub-classes. Perhaps the most consistent result is that the mean value of inheritances of families headed by whites always outstrips that for families headed by African Americans. Somewhat surprisingly, however, this is not always the case at the median. In general, mean inheritances are increasing by wealth class as are median ones, though not as strongly as at the mean. Any tendencies over time, even across surveys with the same length retrospective period, seem to be largely obscured by sampling variability.

Are patterns by income, wealth and demographic group similarly affected in the SCF when the retrospective period is shortened to five years? The tendency for the amount of inheritances to increase with income, wealth and education is probably somewhat more pronounced in the SCF than in the PSID, but there still is not evidence of a strong monotonic relationship (see Table 19). In terms of race, mean inheritances among African American households exceed those of white families in 1998 and are nearly their equal in 1989, though in terms of medians, the inheritances of white households are always higher.

In Table 18, we combine the results of Table 15 and 16 to calculate the mean value of inheritances received among all households in each group. As in the case of 
Table 13, the inheritance patterns are now much sharper and consistent by demographic characteristic. Mean inheritances now almost consistently increase with family income (though the top income class is still a bit of an anomaly) and monotonically increase with family wealth level. Mean inheritances among whites are now about 10 times greater than that of African-Americans in almost all years (2001 is an exception). Mean inheritances increase steadily with age in the 1984 data as expected, since the 1984 figures are the present value of all inheritances received to date. In the other years, with shorter time spans, the pattern is U-shaped in almost all years (1999 and 2001 are exceptions). Mean inheritances rise steadily with educational level, with a five- to ten-fold difference between college graduates and the lowest educational group.

Table 20 presents summary statistics calculated on data from all the PSID wealth supplements combined: the mean and median present value of inheritances by income, wealth and demographic categories. ${ }^{22}$ There is an evident tendency for wealthier families to have inherited higher amounts, as is also the case for older families. The situation is less clear cut by income. By education class, there is an evident distinction between those families headed by college graduates and the rest in terms of mean inheritances, though there is little difference among the education groups when the median is used. White families have much higher mean inheritance levels than African American ones (\$123.1 thousand versus \$54.2 thousand), but the difference at the medians (\$37.4 thousand versus $\$ 34.9$ thousand) is rather small.

A key question of this study is whether there is evidence of a trend in the amounts that families are inheriting. In Table 21, all the PSID data are again used, and years of receipt are combined into five-year intervals by year of inheritance receipt. While the series, which begins with 1910-14, is likely to have been strongly affected by sampling variability, there appears to be evidence that the amount of inheritances has fallen since the mid-1990s.

\footnotetext{
${ }^{22}$ For this and the following table, we created the sample as follows. In each survey year, there is information on either two or three inheritances. For each inheritance from all the years where inheritances were surveyed in this way, we took the year of the inheritance receipt, the amount in \$2007, the weight and demographic characteristics and created a new dataset where the unit of observation is the inheritance. From that database, we then calculated means and medians by demographic characteristic and by year the inheritance was received. In each year, the weights represent population counts.
} 
How unequal is the distribution of inheritances? Evidence on this question is displayed in Table 22. Because the vast majority of families do not report an inheritance for any given survey year, no matter what the length of the retrospective period, it is not surprising that the Gini coefficient among all families is near one in each year. Even when the calculation is restricted to recipients only, there is evidence of considerable inequality. For 1984, with its complete retrospective period, the Gini coefficient is 0.79 . This figure is quite close to the average Gini coefficient of 0.81 derived from the SCF data for years 1989, 1998, and 2007. The PSID Gini coefficient is also higher than for any of the other PSID survey years. This result suggests that as inheritances build up over the lifetime, the degree of inequality of inheritances actually rises rather than falls. Moreover, it does not seem to make a substantial difference whether the retrospective period is two years or five years with regard to Gini coefficients calculated for the other PSID survey years.

It is also of interest is whether there is a time trend in the inequality of inheritances. Looking at the three survey years with 5-year retrospective periods as one group and the four survey years with two-year retrospective periods as another group, one would find it difficult to detect evidence of a time trend.

As a prelude to an assessment of the impact of inheritances on overall wealth inequality, we now examine the present value of inheritances received as a percent of net worth. In the PSID, such an analysis can be done only with the 1984 data, because only for that year is the complete history of inheritances available. For all families, this share is 16.8 percent, as shown in Table 23. While comparisons with the SCF are difficult because the nearest SCF with the appropriate information is 1989, the proportion does fall within the range exhibited with the SCF data, 15.2 percent in 2001 to 31.2 percent in 1995. The share tends to decline with family income, ranging from 32.0 percent for the lowest class to 0.3 percent for the highest. Inheritances as a share of net worth are clearly highest for the lowest wealth class, but there is little difference across the remaining wealth classes. These two sets of results are very similar to those reported on the basis of the SCF data in Section 4.2.

By age, the share climbs almost monotonically with the age of the household head, reaching 67 percent for the oldest age group. By education, the inheritances of 
college graduates are a higher share of net worth than for the other schooling groups. By race, the share is higher for white families (17 percent) than it is for African American families (9 percent). In contrast to the PSID results by income and wealth class, these findings actually differ substantially from those derived from the SCF data. As shown in Section 4.1, the share of inheritances in net worth has a U-shaped relationship to age class, falling from the youngest age group to age group 55-64 and then rising. The share is also almost invariant across educational groups in the SCF data and, most notably, the share is greater for African-American households than white households in the SCF results.

To assess the effect of inheritances on the inequality of wealth, we conducted an exercise similar to that in Section 4.2, where the square of the coefficient of variation is decomposed into its various components. The results from the PSID for year 1984 are shown in Table 24. It is first of note that the correlation between total net worth excluding inheritances (NWX) and inheritances (IN) is -0.31 , indicating that inheritances serve to reduce overall wealth inequality (the fifth line of panel A). The corresponding correlation coefficients from the SCF data range from -0.11 for 2001 to -0.80 for 2004 and average - 0.50 over the 7 survey years from 1989 to 2007.

The distribution of inheritances is, however, much more skewed than the distribution of net worth excluding transfers: the former has a coefficient of variation of 17.2 and the latter one of 5.1. Thus, the net effect of inheritances on overall wealth inequality hinges on the relative magnitude of the three components. The covariation effect is stronger, leading to a reduction in wealth inequality: the coefficient of variation of wealth including inheritances is 15 percent lower than without them. Thus, as was the case in the SCF data, the net effect of inheritances is actually to equalize the overall distribution of wealth.

\section{Concluding Remarks}

We found on the basis of the SCF data that on average over the period from 1989 to 200721 percent of American households at a given point of time received a wealth transfer and these accounted for 23 percent of their net worth. These figures are comparable to previous studies of inheritances in the U.S. However, over the lifetime, 
about 30 percent of households could expect to receive a wealth transfer, the mean value of these transfers would be about $\$ 200,000$ (in 2007 dollars), and these would account for close to 40 percent of their net worth near time of death. The PSID data yield very similar results.

With regard to the first major issue raised in the Introduction, somewhat surprisingly, we found on the basis of both the SCF and the 1984 PSID (which has data on inheritances received over the whole lifetime of the respondent, up to current age), that inheritances and other wealth transfers tend to be equalizing in terms of the distribution of household wealth. Indeed, the addition of wealth transfers to other sources of household wealth had a sizeable effect on reducing the inequality of wealth. The results appear counter-intuitive. Richer households do receive greater inheritances and other wealth transfers than poorer households. However, as a proportion of their current wealth holdings, wealth transfers are actually greater for poorer households than richer ones. That is to say, a small gift to the poor means more than a large gift to the rich.

A related (also surprising) finding is that even though white households receive larger wealth transfers than African-Americans, a higher fraction of the wealth of African-Americans (about a third) comes from wealth transfers than that of whites (about a fifth). Low income households and the young and old (particularly, households age 75 and over) also receive a higher share of their wealth from transfers relative to other groups. However, on the basis of the one-year, five-year, and two-year periods covered by the retrospective inheritance questions in the PSID, we find an inverted U-shaped pattern between the value of inheritances received and age class, with a peak generally at age class 55 to 64 .

Our key finding that wealth transfers are equalizing in terms of the distribution of wealth requires several qualifications. In particular, we have to be careful what counterfactuals are being assumed when we reach this conclusion. Eliminating wealth transfers would affect the behavior of both donors and recipients. Our implicit assumption in the decompositions reported above is that if wealth transfers are eliminated, there is no effect on the savings behavior of those who have received transfers or are expecting them and that there is no effect on the savings of those who intend to give a bequest. 
As we indicated above, it is beyond the scope of the paper to model these effects but we should add a few caveats to the conclusions about the equalizing impact of wealth transfers. In particular, our assumption that eliminating wealth transfers will have a relatively small effect on savings behavior might not be that unreasonable - that is, the bequest motive may not be that strong. Inheritances will affect the behavior of their recipients, with some difference in the impact depending on whether or not the inheritance was anticipated. While we do not explicitly talk about anticipated versus unanticipated bequests, prior simulation results of ours (not shown here) suggest that the equalizing effect of wealth transfers holds up through a wide range of values of the elasticity of substitution between (active) savings and wealth transfers.

However, one might also want to consider the following scenario: Suppose that the estate tax is to become confiscatory. What would happen to the savings behavior of those who intend to leave bequests and how would this affect the distribution of wealth? In other words, what are the effects on the distribution of wealth of changes in savings behavior of those intending to leave bequests?

A full analysis of this scenario would be beyond the scope of the present chapter. However, there is prior work which might bolster the credibility of our results. For example, Dynan, Skinner and Zeldes (2002) claim "that allowing for uncertainty resolves the controversy over the importance of life-cycle and bequest saving by showing that these motives for saving are overlapping and cannot generally be distinguished. A dollar saved today simultaneously serves both a precautionary life-cycle function, guarding against future contingencies such as health shocks or other emergencies, and a bequest function because - in the likely event that these contingencies do not absorb the dollar — it will be available to bequeath to children or other worthy causes.” In their model, if there was a confiscatory estate and gift tax, savings behavior would change only modestly for all but the very wealthy.

Moreover, in the more recent work of Kopczuk and Lupton (2007), it is concluded that three-fourths of the individuals in their sample have a bequest motive. While this, at first, seems to be at odds with Dynan, Skinner and Zeldes (2002), the implications turn out to be similar. Kopczuk and Lupton "find that most of the population has a bequest motive but for a majority, at least, some of bequests are of an 
accidental nature. Only at high wealth levels does the difference between having and not having a bequest motive become clearly visible. A tax on small bequests is unlikely to have a large impact on individual decisions, while a tax on large bequests may be distortionary because some of the large bequests appear motivated by bequest considerations.”

The second main issue is whether inheritances and other wealth transfers have become more important over time. Our SCF results indicate that over the period from 1989 to 2007, the share of households reporting a wealth transfer fell by 2.5 percentage points. However, the mean and median value of wealth transfers among recipients climbed over the period, by 23 percent for the former and 36 percent for the latter. The average value of inheritances received among all households did increase but at a slower pace, by 10 percent. However, wealth transfers as a proportion of current net worth fell sharply over this period from 29 to 19 percent or by 10 percentage points. Moreover, though the share of households reporting a wealth transfer in the five and ten years preceding the survey year each increased slightly from 1989 to 2007 and the average value of these transfers among recipients rose by 33 percent for the five years preceding and 58 percent for the 10 years preceding, these transfers as shares of net worth declined in both cases. The PSID results yield similar findings. In particular, we could find no evidence that inheritances are growing in importance over time. This was true in terms of the percentage of households receiving an inheritance, the mean and median value of inheritances among recipients, and the mean value among all households.

Thus, despite the fact that the baby boom generation was reaching "prime” inheritance age and the wealth of their parents was the highest in history for that age group, wealth transfers were less important in accounting for current net worth in 2007 than in 1989. There are several possible explanations. First, the early and mid 2000s (from 2001 to 2007) was a period of very high capital gains and consequently very rapid household wealth growth, particularly because of the boom in housing prices and, to a lesser extent, stock prices. This would make inheritances less important as a source of wealth accumulation when capital gains are strong. Second, life spans rose over this period. Since elderly people were living longer, the number of bequests per year declined. Indeed, richer people tend to live longer than poorer ones and the gap in life expectancies 
may also have risen over time. This trend would also lower the number of large bequests received per year.

Third, as people live longer, their medical expenses might rise as they age and, as a result, less money is transferred to children at time of death. Fourth, the share of estates dedicated to charitable contributions might be rising over time. This trend may be particularly characteristic of the rich.

Fifth, it is possible that inheritances and other wealth transfers are sensitive to the business cycle. One can think of both a demand for and supply of wealth transfers. If (older) people are becoming richer because of an economic expansion, then the likelihood of making a wealth transfer and the size of the wealth transfer may increase. On the other hand, if their children are also benefiting from the economic expansion and their incomes are rising, then the need for a gift or bequest from their parents may decline and wealth transfers may fall. Conversely, if younger people are becoming poorer because of a business cycle downturn, then the need for a gift or inheritance may increase. However, if their parents are also affected by the economic downturn, then the likelihood of a wealth transfer and its size may also fall. The net effect in both cases is hard to discern, and, in any case, all the years in our sample with the exception of recession year 1992 were at or close to the peak of a business cycle boom.

With regard to the very rich, the share of households receiving a wealth transfer in the top income class, as well as the mean and median value of the transfer among recipients, fell off between 1989 and 2007. Among millionaires in terms of wealth, the share of households receiving a transfer and the average value of the transfers among recipients also declined over these years, though the median value of the transfers among recipients increased. Among the top one percent of the wealth distribution, the share receiving a transfer decreased but the mean value of the transfers among recipients as well as the average value among all households in the group rose over the period. Nonetheless, for all three groups of rich households, wealth transfers as a share of their net worth fell between 1989 and 2007. The same trend held true for college graduates. It is therefore reasonable to conclude that inheritances and other wealth transfers have become less important for the rich as a source of wealth accumulation over these years. 
Our third main issue is whether the inequality of wealth transfers rose over time. We found first of all that the inequality of wealth transfers is extremely high. For 1998, on the basis of the SCF data, the Gini coefficient of transfers among all households is 0.96 and among recipients only it is 0.80 . This compares to a Gini coefficient for net worth in 1998 of 0.82 . However, there is no indication that the inequality of wealth transfers increased over time. In fact, the Gini coefficient for all households remained unchanged and that for recipients only fell slightly from 1989 to 2007. Moreover, as in the case of the SCF data, there is no detectable evidence on the basis of the PSID that the inequality of inheritances either increased or declined over the years from 1984 to 2007.

Moreover, the proportion of households receiving a wealth transfer climbed sharply with both household income and wealth, as did the mean and median values of these transfers among recipients and among all households in the income and wealth classes. However, as a share of net worth, wealth transfers declined sharply with both income and wealth level. As a result, net worth excluding wealth transfers and wealth transfers themselves are negatively correlated.

We might also speculate, somewhat surprisingly, that the lower wealth inequality found in European countries compared to the U.S. might be due to larger inheritances (at least as indicated in the French and Swedish household surveys). Indeed, Pestieau (2001) reports that the share of bequests in total household wealth is higher in France and Europe than in the U.S.

Our main finding is that inheritances are an equalizing force in terms of the distribution of household wealth. From the standpoint of equity, a tax structure on bequests should provide, firstly, an incentive for wealth transfers and, secondly, greater benefits (that is, lower taxes) on gifts to the less wealthy. The results also suggest that the current structure of the estate tax is quite good from the standpoint of equity. The estate tax exempts relatively small wealth transfers (including gifts), whereas it taxes large ones. Small transfers are equalizing in terms of wealth and should be maintained.

Indeed, one might even speculate that an inheritance tax as found in many European countries, where individual inheritances are taxed rather than the full size of the estate, might be superior to an estate tax from the point of view of equity. An inheritance tax has more flexibility than the estate tax. In particular, it encourages the disposition of 
an estate into a number of small bequests, since the bequests are individually taxed. Second, it allows for the possibility of a "means-tested" tax on bequests. As with the current estate tax, the marginal tax rate would increase with the level of wealth transferred in the inheritance. However, the marginal tax rates could be set lower for recipients with lower income or wealth.

Two provisos for these results should also be mentioned. First, we have assumed that the under-reporting biases (which likely exist in the recall method) are not systematically correlated with the level of household wealth. If the under-reporting bias is greater for richer households, then the equalizing effect of wealth transfers will be overstated. Second, we have used a three-percent capitalization rule for all inheritances and other wealth transfers. If we count the full capital gains received on wealth transfers, then this method might raise the value of wealth transfers of the rich relative to the poor. 


\section{$\underline{\text { References }}$}

Avery, Robert B., and Michael S. Rendall (1993), "Estimating the Size and Distribution of Baby Boomers' Prospective Inheritances," in the American Statistical Association's 1993 Proceedings of the Social Statistics Section, pp. 11-19.

Barlow, R., Harvey E. Brazer, James N. Morgan (1966), Economic Behavior of the Affluent, Washington, D.C.: The Brookings Institution.

Brown, Jeffrey R. and Scott J. Weisbenner (2004), “Intergenerational Transfers and Savings Behavior.” In David A. Wise, Editor, Perspectives on the Economics of Aging, Chicago: University of Chicago Press, pp. 181-204.

David, Martin, and Paul L. Menchik (1982), "Distribution of Estates and Its Relationship to Intergenerational Transfers," Statistics of Income and Related Administration Record Research.

Dynan, Karen E., Jonathan Skinner and Stephen P. Zeldes (2004), “Do the Rich Save More?” Journal of Political Economy, Vol. 112, no. 2, pp. 397-444.

Gale, William G., and J.K. Scholz (1994), “Intergenerational Transfers and the Accumulation of Wealth,” Journal of Economic Perspectives, Vol. 8, pp. 145-160.

Greenwood, Daphne T., and Edward N. Wolff (1992), "Changes in Wealth in the United States, 1962 - 1983: Savings, Capital Gains, Inheritance, and Lifetime Transfers," Journal of Population Economics, Vol. 5, No. 4, pp. 261-288.

Hurd, Michael D., and Gabriella Mundaca (1989), "The Importance of Gifts and Inheritances among the Affluent." In Robert E. Lipsey and Helen Stone Tice eds., The Measurement of Saving, Investment, and Wealth, Studies of Income and Wealth, Vol. 52. Chicago: Chicago University Press, pp. 737-763.

Kennickell, Arthur B. 2001. "Modeling Wealth with Multiple Observations of Income: Redesign of the Sample for the 2001 Survey of Consumer Finances," October, http://www.federalreserve.gov/pubs/oss/oss2/method.html.

Kessler, Denis, and Andre Masson (1979), "Les transferts intergenerationales: l'aide, la donation, l'heritage," C.N.R.S. Report, Paris.

Kessler, Denis, and Andre Masson (1989), "Bequests and Wealth Accumulation: Are Some Pieces of the Puzzle Missing," Journal of Economic Perspectives, Vol. 3, No. 3, pp.141-152. 
Klevmarken, N. Anders (2001), "On the Wealth Dynamics of Swedish Families 1984-1998," paper presented at the $21^{\text {st }}$ Arne Ryde Symposium on Non-Human Wealth and Capital Accumulation, August 23-25, 2001, Lund, Sweden.

Kopczuk, Wojciech, and Joseph P. Lupton (2007), “To Leave or Not to Leave: The Distribution of Bequest Motives,” Review of Economic Studies, Vol. 74, pp. 207235.

Laitner, John (1992), "Random Earnings Differences, Lifetime Liquidity Constraints, and Altruistic Intergenerational Transfers, Journal of Economic Theory, Vol. 58, pp.135-170.

Laitner, John and Henry Ohlsson (2001), "Bequest Motives: A Comparison of Sweden and the United States,” Journal of Public Economics, January 2001, Vol. 79, No. 1, pp. 205-36.

Laitner, John and Amanda Sonnega (2010), "Intergenerational Transfers in the Health and Retirement Study Data,” Michigan Retirement Research Center, Ann Arbor, MI, November.

Menchik, Paul and Martin David (1983), "Income Distribution, Lifetime Saving and Bequests," American Economic Review, September.

Morgan, James N., Martin H. David, William. J. Cohen, and Harvey E. Brazer (1962), Income and Welfare in the United States, New York: McGraw-Hill Book Company.

Pestieau, Pierre (2001), "The Role of Gifts and Estate Transfers in the United States and Europe," mimeo.

Projector, Dorothy and Gertrude Weiss (1966), "Survey of Financial Characteristics of Consumers," Federal Reserve Technical Papers.

Schervish, Paul G., and John J. Havens (1999), “Millionaires and the Millennium: New Estimates of the Forthcoming Wealth Transfer and the Prospects for a Golden Age of Philanthropy,” Social Welfare Research Institute of Boston College, Boston, MA.

Wolff, Edward N. (1987), "The Effects of Pensions and Social Security on the Distribution of Wealth in the U.S." In Edward N. Wolff ed., International Comparisons of Household Wealth Distribution, Oxford: Oxford University Press, pp. 208-247. 
Wolff, Edward N. (1999), "Wealth Accumulation by Age Cohort in the U.S., 1962-1992: The Role of Savings, Capital Gains and Intergenerational Transfers," Geneva Papers on Risk and Insurance, Vol. 24, No. 1, January, pp. 27-49.

Wolff, Edward N. (2002), "Inheritances and Wealth Inequality, 1989-1998," American Economic Review Papers and Proceedings, Vol. 92, No. 2, May, pp. 260-264. Wolff, Edward N. (2003), "The Impact of Gifts and Bequests on the Distribution of Wealth," in Alicia H. Munnell and Annika Sundén editors, Death and Dollars, Washington, DC: Brookings Institution, pp. 345-375.

Wolff, Edward N. (2010), "Recent Trends in Household Wealth in the United States: Rising Debt and the Middle-Class Squeeze - An Update to 2007,” Annandale-onthe Hudson, NY: Levy Economics Institute Working Paper No. 589, March.

Wolff, Edward N., Ajit Zacharias, and Thomas Masterson (2009), "Trends in American Living Standards and Inequality, 1959-2004.” Annandale-on the Hudson, NY: Levy Economics Institute, mimeo, December. 


\begin{tabular}{|c|c|c|c|c|c|c|c|c|c|c|c|c|c|c|}
\hline \multirow[b]{2}{*}{ Recipients of: } & \multicolumn{7}{|c|}{$\begin{array}{l}\text { Percent of Households Indicating a Transfer of the } \\
\text { Indicated Type }\end{array}$} & \multicolumn{7}{|c|}{$\begin{array}{l}\text { Mean Present Value of Wealth Transfer by Indicated } \\
\text { Type for Recipients Only }\end{array}$} \\
\hline & 1989 & 1992 & 1995 & 1998 & 2001 & 2004 & 2007 & 1989 & 1992 & 1995 & 1998 & 2001 & 2004 & 2007 \\
\hline General wealth transfer questions ${ }^{a}$ & 23.1 & 20.5 & 21.3 & 20.3 & 17.8 & 20.3 & 21.0 & 370.3 & 372.8 & 347.0 & 276.0 & 292.8 & 480.5 & 416.6 \\
\hline 1. Owner-occupied housing ${ }^{b}$ & 2.8 & 2.2 & 3.2 & 3.1 & 3.0 & 2.7 & 2.8 & 180.3 & 206.7 & 205.6 & 241.1 & 220.3 & 297.1 & 438.7 \\
\hline 2. Other real estate ${ }^{c}$ & 4.1 & 2.3 & 4.4 & 3.1 & 2.7 & 3.2 & 3.5 & 266.6 & 410.3 & 296.9 & 344.3 & 691.6 & 590.5 & 420.1 \\
\hline 3. Business ${ }^{d}$ & 0.6 & 0.3 & 0.5 & 0.4 & 0.3 & 0.3 & 0.7 & 1337.0 & 1529.9 & 2681.3 & 966.6 & 1315.7 & 1908.6 & 1674.1 \\
\hline $\begin{array}{l}\text { 4. Real estate or business } \\
\text { FINAL ESTIMATE: }\end{array}$ & 7.6 & 5.0 & 7.8 & 6.5 & 5.9 & 6.1 & 6.5 & 315.3 & 386.5 & 436.9 & 334.9 & 498.1 & 543.8 & 586.6 \\
\hline $\begin{array}{l}\text { 5. General wealth transfer } \\
\text { and/or real estate or business }{ }^{\mathrm{e}} \\
\text { DISCREPANCY: }\end{array}$ & 23.5 & 20.7 & 21.4 & 20.4 & 17.9 & 20.3 & 21.1 & 387.1 & 402.8 & 406.7 & 323.5 & 378.6 & 516.5 & 476.2 \\
\hline $\begin{array}{l}\text { 6. Real estate or business but } \\
\text { NOT general wealth transfer }\end{array}$ & 0.4 & 0.2 & 0.1 & 0.0 & 0.0 & 0.0 & 0.1 & 16.8 & 30.1 & 59.7 & 47.5 & 85.8 & 36.0 & 59.6 \\
\hline \multicolumn{15}{|c|}{$\begin{array}{l}\text { Note: own computations from the } 1989,1992,1995,1998,2001,2004 \text {, and } 2007 \text { Survey of Consumer Fina } \\
\text { a. Question corresponding to variables X5803, X5808, and X } 5813 \text {. } \\
\text { b. Includes mobile homes and sites as well as farm and ranch houses. } \\
\text { c. Includes vacation properties, time-shares, and investment real estate. } \\
\text { d. Active businesses only. Transfer information is missing for passive businesses. } \\
\text { e. In the final estimate, we include a transfer of real estate or business only if there is no corresponding ge } \\
\text { f. The "discrepancy" shows the difference between the answers to the general wealth transfer question } \\
\text { and our "final estimate." } \\
\text { g. The figures are based on the present value of all transfers as of the survey year which were received up } \\
\text { to the time of the survey and accumulated at a real interest rate of } 3.0 \text { percent for recipients only. }\end{array}$} \\
\hline
\end{tabular}




\begin{tabular}{|c|c|c|c|c|c|c|c|c|c|c|c|c|c|c|}
\hline & \multicolumn{7}{|c|}{$\begin{array}{l}\text { Percent of Wealth Transfer Recipients } \\
\text { Receiving Indicated Type of Transfer }^{\mathrm{a}}\end{array}$} & \multicolumn{7}{|c|}{$\begin{array}{l}\text { Present Value of Transfer Received as } \\
\text { A Percent of Total Wealth Transfers }\end{array}$} \\
\hline & 1989 & 1992 & 1995 & 1998 & 2001 & 2004 & 2007 & 1989 & 1992 & 1995 & 1998 & 2001 & 2004 & 2007 \\
\hline All Transfer Recipients & 100.0 & 100.0 & 100.0 & 100.0 & 100.0 & 100.0 & 100.0 & 100.0 & 100.0 & 100.0 & 100.0 & 100.0 & 100.0 & 100.0 \\
\hline 1. Inheritances only & 85.2 & 88.1 & 74.9 & 76.2 & 78.0 & 80.7 & 77.7 & 64.5 & 75.8 & 80.2 & 76.4 & 80.2 & 55.6 & 73.6 \\
\hline 2. Gifts or transfers only & 3.5 & 5.2 & 14.6 & 17.2 & 14.3 & 11.6 & 14.2 & 1.5 & 1.9 & 4.8 & 9.7 & 5.9 & 3.8 & 8.9 \\
\hline 3. Trust funds or other only & 7.7 & 3.3 & 6.2 & 3.0 & 3.1 & 2.2 & 3.1 & 11.1 & 8.4 & 4.9 & 6.1 & 5.8 & 4.5 & 6.8 \\
\hline 4. Inheritances and gifts & 0.6 & 1.7 & 2.5 & 2.2 & 3.2 & 3.5 & 3.6 & 1.4 & 1.0 & 1.6 & 2.0 & 2.4 & 4.7 & 4.5 \\
\hline 5. Inheritances and trusts & 2.9 & 1.4 & 1.7 & 1.3 & 1.2 & 1.7 & 1.0 & 21.4 & 5.1 & 3.5 & 5.5 & 5.0 & 28.4 & 5.2 \\
\hline 6. Gifts and trusts & 0.1 & 0.1 & 0.1 & 0.1 & 0.3 & 0.3 & 0.4 & 0.1 & 6.9 & 0.3 & 0.3 & 0.3 & 3.1 & 0.9 \\
\hline $\begin{array}{l}\text { 6. Inheritances, gifts and } \\
\text { trusts }\end{array}$ & $\mathbf{0 . 0}$ & 0.3 & 0.0 & 0.0 & 0.1 & 0.0 & 0.0 & 0.0 & 0.8 & 4.7 & 0.0 & 0.4 & 0.0 & $\mathbf{0 . 0}$ \\
\hline \multicolumn{15}{|l|}{ Memo: } \\
\hline All Transfer Recipients & & & & & & & & 100.0 & 100.0 & 100.0 & 100.0 & 100.0 & 100.0 & 100.0 \\
\hline 1. All Inheritances & 88.7 & 91.4 & 79.2 & 79.7 & 82.4 & 85.8 & 82.3 & 76.9 & 78.6 & 87.4 & 79.7 & 83.6 & 63.2 & 78.8 \\
\hline 2. All gifts or transfers & 4.2 & 7.3 & 17.2 & 19.4 & 17.8 & 15.4 & 18.2 & 1.7 & 2.5 & 5.6 & 10.8 & 7.2 & 5.2 & 10.2 \\
\hline $\begin{array}{l}\text { 3. All trust funds or other } \\
\text { transfers. }\end{array}$ & 10.7 & 5.0 & 8.0 & 4.4 & 4.6 & 4.3 & 4.5 & 21.4 & 19.0 & 7.0 & 9.5 & 9.2 & 31.6 & 10.9 \\
\hline \multicolumn{15}{|c|}{$\begin{array}{l}\text { Note: own computations from the } 1989,1992,1995,1998,2001,2004 \text {, and } 2007 \text { SCF. Tabulations are } \\
\text { only for general wealth transfer questions. } \\
\text { a. Inheritances include inherited trust funds. } \\
\text { b. The column sum is greater than unity since a household may receive more than one type of transfer. } \\
\text { c. The figures are based on the present value of all transfers as of the survey year which were received up } \\
\text { to the time of the survey and accumulated at a real interest rate of } 3.0 \text { percent) for inheritors only. }\end{array}$} \\
\hline
\end{tabular}




\begin{tabular}{|c|c|c|c|c|c|c|c|c|c|c|c|c|c|c|}
\hline & \multicolumn{7}{|c|}{$\begin{array}{l}\text { Percent of Wealth Transfer Recipients by Indicated Source } \\
\text { of Transfer }^{\mathrm{a}}\end{array}$} & \multicolumn{7}{|c|}{$\begin{array}{l}\text { Present Value of Transfer Received as } \\
\text { A Percent of Total Wealth Transfers }{ }^{c}\end{array}$} \\
\hline & 1989 & 1992 & 1995 & 1998 & 2001 & 2004 & 2007 & 1989 & 1992 & 1995 & 1998 & 2001 & 2004 & 2007 \\
\hline All Transfer Recipients & 100.0 & 100.0 & 100.0 & 100.0 & 100.0 & 100.0 & 100.0 & 100.0 & 100.0 & 100.0 & 100.0 & 100.0 & 100.0 & 100.0 \\
\hline 1. Parents only & 49.2 & 47.9 & 57.7 & 60.8 & 62.2 & 55.9 & 61.6 & 35.5 & 35.3 & 41.2 & 52.0 & 64.4 & 44.0 & 59.9 \\
\hline 4. Friends and others only & 5.4 & 3.1 & 3.0 & 2.9 & 2.2 & 2.3 & 1.7 & 9.3 & 4.8 & 1.4 & 3.0 & 1.7 & 1.3 & 0.5 \\
\hline 5. Two or more relatives & 11.9 & 13.8 & 11.2 & 10.7 & 7.8 & 10.3 & 10.8 & 24.3 & 37.3 & 18.9 & 29.2 & 15.8 & 36.7 & 27.6 \\
\hline $\begin{array}{l}\text { 6. Relatives and friends } \\
\text { or others }\end{array}$ & 3.9 & 2.4 & 2.0 & 1.7 & 1.3 & 1.0 & 1.0 & 17.9 & 7.6 & 3.9 & 2.9 & 2.4 & 1.7 & 1.5 \\
\hline \multicolumn{15}{|l|}{ Memo: } \\
\hline 4. Friends and others & 4.7 & 5.4 & 5.0 & 4.7 & 3.5 & 3.3 & 2.7 & 10.1 & 4.6 & 1.5 & 3.0 & 1.7 & 1.3 & 0.5 \\
\hline \multicolumn{15}{|c|}{$\begin{array}{l}\text { Note: own computations from the } 1989,1992,1995,1998,2001,2004 \text {, and } 2007 \text { SCF. Tabulations are } \\
\text { only for general wealth transfer questions. } \\
\text { a. Inheritances include inherited trust funds. } \\
\text { b. The column sum is greater than unity since a household may receive more than one type of transfer. } \\
\text { c. The figures are based on the present value of all transfers as of the survey year which were received up } \\
\text { to the time of the survey and accumulated at a real interest rate of } 3.0 \text { percent for recipients only. }\end{array}$} \\
\hline
\end{tabular}




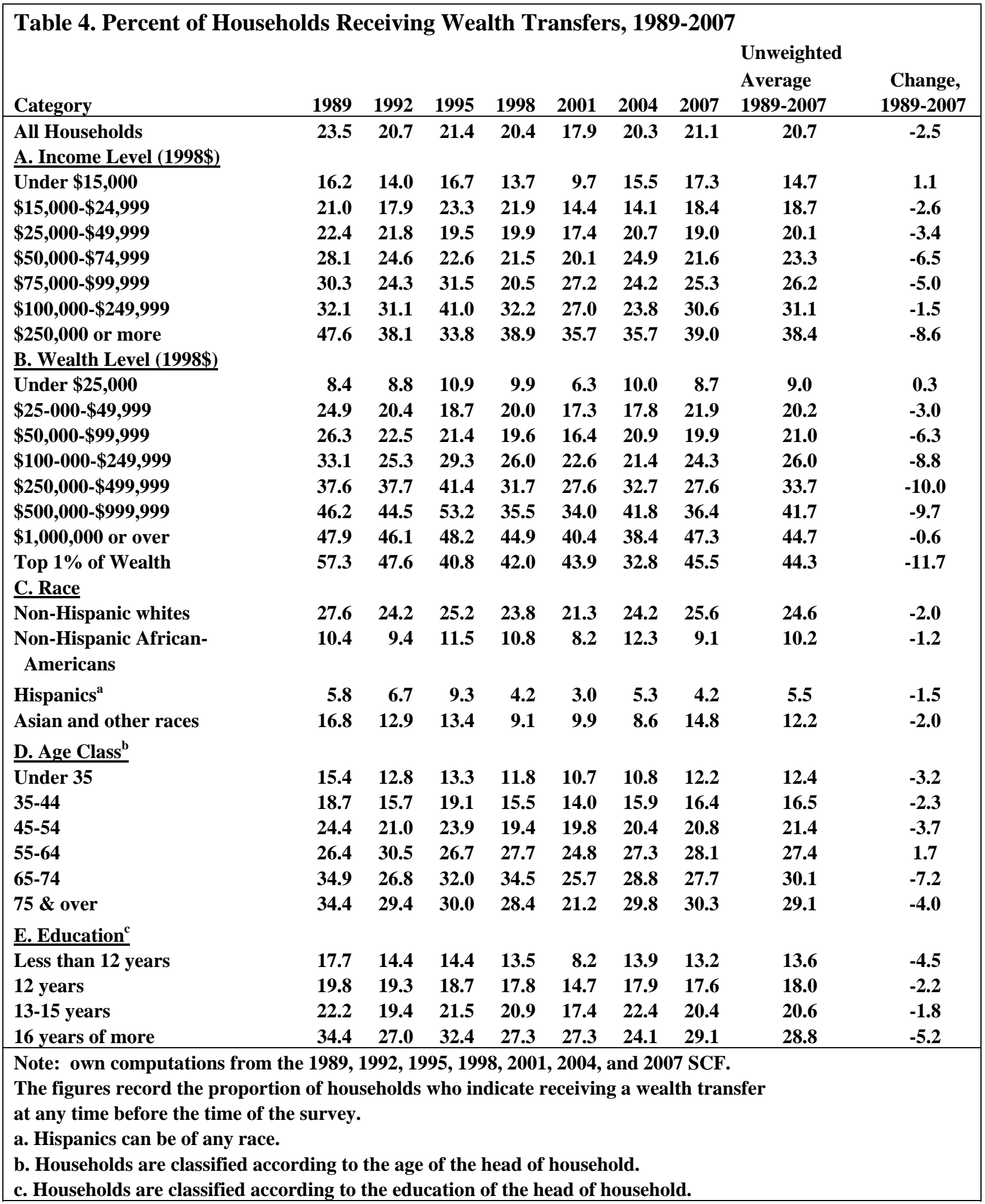




\begin{tabular}{|c|c|c|c|c|c|c|c|c|c|}
\hline \multicolumn{10}{|c|}{$\begin{array}{l}\text { Table 5. Mean Present Value c } \\
\text { (Figures are in 1000s, } 2007 \text { dollars) }\end{array}$} \\
\hline 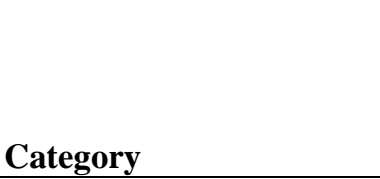 & 1989 & 1992 & 1995 & 1998 & 2001 & 2004 & \multicolumn{2}{|c|}{$\begin{array}{rl} & \text { Unweighted } \\
& \text { Average } \\
2007 & 1989-2007\end{array}$} & $\begin{array}{c}\% \\
\text { Change, } \\
\text { 1989-2007 }\end{array}$ \\
\hline $\begin{array}{l}\text { All Households } \\
\text { A. Income Level (1998\$) }\end{array}$ & 387.1 & 402.8 & 406.7 & 323.5 & 378.6 & 516.5 & 476.2 & 413.1 & 23.0 \\
\hline Under $\$ 15,000$ & 126.4 & 195.7 & 214.7 & 198.4 & 155.6 & 822.2 & 242.6 & 279.4 & 91.9 \\
\hline$\$ 15,000-\$ 24,999$ & 240.4 & 163.9 & 134.3 & 182.8 & 222.7 & 275.6 & 246.7 & 209.5 & 2.6 \\
\hline$\$ 25,000-\$ 49,999$ & 207.8 & 317.1 & 207.6 & 267.3 & 355.1 & 226.5 & 291.7 & 267.6 & 40.4 \\
\hline$\$ 50,000-\$ 74,999$ & 213.9 & 313.5 & 584.5 & 173.5 & 380.0 & 291.2 & 280.4 & 319.6 & 31.1 \\
\hline$\$ 75,000-\$ 99,999$ & 529.3 & 489.2 & 900.5 & 228.6 & 313.5 & 277.5 & 422.7 & 451.6 & -20.1 \\
\hline$\$ 100,000-\$ 249,999$ & 835.8 & 934.3 & 535.3 & 466.3 & 502.8 & 615.6 & 871.9 & 680.3 & 4.3 \\
\hline $\begin{array}{l}\$ 250,000 \text { or more } \\
\text { B. Wealth Level }(1998 \$)\end{array}$ & 3468.1 & 3258.4 & 4066.0 & 2828.9 & 1222.9 & 3915.5 & 2678.4 & 3062.6 & -22.8 \\
\hline Under $\$ 25,000$ & 83.6 & 45.2 & 37.8 & 67.7 & 66.0 & 45.1 & 70.0 & 59.3 & -16.3 \\
\hline \$25-000-\$49,999 & 91.2 & 63.6 & 143.0 & 108.1 & 103.9 & 300.7 & 67.4 & 125.4 & -26.1 \\
\hline$\$ 50,000-\$ 99,999$ & 82.0 & 151.0 & 200.9 & 132.8 & 91.0 & 379.4 & 113.0 & 164.3 & 37.8 \\
\hline$\$ 100-000-\$ 249,999$ & 161.4 & 205.9 & 201.2 & 155.8 & 152.5 & 436.7 & 211.3 & 217.8 & 30.9 \\
\hline$\$ 250,000-\$ 499,999$ & 269.1 & 217.8 & 313.6 & 230.0 & 663.8 & 235.2 & 305.9 & 319.3 & 13.6 \\
\hline$\$ 500,000-\$ 999,999$ & 536.9 & 1096.4 & 1113.7 & 547.2 & 449.6 & 484.0 & 571.0 & 685.5 & 6.3 \\
\hline $\begin{array}{l}\$ 1,000,000 \text { or over } \\
\text { C. Race }\end{array}$ & 2,188 & 2,607 & 2,207 & 1,635 & 1,015 & 2,271 & 1,842 & 1966.4 & -15.8 \\
\hline Non-Hispanic whites & 356.9 & 398.1 & 426.4 & 333.2 & 400.0 & 537.7 & 482.4 & 419.3 & 35.2 \\
\hline $\begin{array}{l}\text { Non-Hispanic African- } \\
\text { Americans }\end{array}$ & 169.2 & 99.5 & 235.0 & 219.5 & 179.6 & 488.2 & 282.6 & 239.1 & 67.1 \\
\hline Hispanics $^{\text {a }}$ & 1695.1 & 50.4 & 83.7 & 150.9 & 52.3 & 107.9 & 466.3 & 372.4 & -72.5 \\
\hline Asian and other races & 281.8 & 413.9 & 452.8 & 346.7 & 175.4 & 107.7 & 655.9 & 347.8 & 132.7 \\
\hline D. Age Class & & & & & & & & & \\
\hline Under 35 & 199.2 & 131.4 & 100.2 & 140.2 & 103.0 & 159.1 & 191.7 & 146.4 & -3.8 \\
\hline $35-44$ & 266.1 & 137.8 & 455.6 & 177.5 & 359.7 & 307.7 & 352.2 & 293.8 & 32.4 \\
\hline $45-54$ & 260.1 & 703.6 & 428.7 & 265.1 & 437.8 & 362.4 & 422.2 & 411.4 & 62.3 \\
\hline $55-64$ & 278.5 & 404.6 & 286.7 & 346.2 & 407.0 & 1024.9 & 492.6 & 462.9 & 76.9 \\
\hline $65-74$ & 877.0 & 508.9 & 438.8 & 333.9 & 368.0 & 502.5 & 749.1 & 539.7 & -14.6 \\
\hline 75 \& over & 385.8 & 564.4 & 735.9 & 714.6 & 571.2 & 557.7 & 635.4 & 595.0 & 64.7 \\
\hline E. Education $^{b}$ & & & & & & & & & \\
\hline Less than 12 years & 198.9 & 100.6 & 171.4 & 144.5 & 121.7 & 516.2 & 183.6 & 205.3 & -7.7 \\
\hline 12 years & 167.0 & 340.2 & 161.9 & 230.5 & 281.5 & 426.3 & 203.7 & 258.7 & 22.0 \\
\hline 13-15 years & 274.2 & 262.4 & 463.6 & 209.2 & 431.6 & 243.8 & 323.3 & 315.4 & 17.9 \\
\hline 16 years of more & 719.2 & 642.5 & 607.1 & 521.1 & 452.0 & 758.0 & 792.4 & 641.8 & 10.2 \\
\hline
\end{tabular}




\begin{tabular}{|c|c|c|c|c|c|c|c|c|c|}
\hline $\begin{array}{l}\text { Table 6. Median Pre } \\
\text { (Figures are in 1000s, } 20\end{array}$ & $\begin{array}{l}\text { alue of } \\
\text { rs) }\end{array}$ & eal & Tran & fers I & ceiv & by & cipi & ts Only, 1 & -2007 \\
\hline & & & & & & & & Unweighted & \\
\hline Category & 1989 & 1992 & 1995 & 1998 & 2001 & 2004 & 2007 & $\begin{array}{l}\text { Average } \\
1989-2007\end{array}$ & $\begin{array}{l}\text { \% Change, } \\
\text { 1989-2007 }\end{array}$ \\
\hline All Households & 66.1 & 63.6 & 65.0 & 71.0 & 86.2 & 73.6 & 89.7 & 73.6 & 35.7 \\
\hline A. Income Level (1998\$) & & & & & & & & & \\
\hline Under $\$ 15,000$ & 41.1 & 39.4 & 55.6 & 43.2 & 68.8 & 54.9 & 74.3 & 53.9 & 80.9 \\
\hline$\$ 15,000-\$ 24,999$ & 67.4 & 47.6 & 41.6 & 52.4 & 56.5 & 49.9 & 52.4 & 52.6 & -22.3 \\
\hline$\$ 25,000-\$ 49,999$ & 61.6 & 63.3 & 52.6 & 78.3 & 90.7 & 56.7 & 65.3 & 66.9 & 6.0 \\
\hline$\$ 50,000-\$ 74,999$ & 58.7 & 70.9 & 78.0 & 65.3 & 78.2 & 92.0 & 74.3 & 73.9 & 26.6 \\
\hline$\$ 75,000-\$ 99,999$ & 89.3 & 84.8 & 98.7 & 78.9 & 78.2 & 84.5 & 104.0 & 88.3 & 16.5 \\
\hline$\$ 100,000-\$ 249,999$ & 152.1 & 168.4 & 100.9 & 120.5 & 176.5 & 137.5 & 170.8 & 146.7 & 12.3 \\
\hline$\$ 250,000$ or more & 461.9 & 214.0 & 272.1 & 318.0 & 244.3 & 340.7 & 389.2 & 320.0 & -15.7 \\
\hline B. Wealth Level (1998\$) & & & & & & & & & \\
\hline Under $\$ 25,000$ & 18.4 & 15.5 & 18.4 & 24.2 & 27.7 & 18.7 & 23.4 & 20.9 & 27.2 \\
\hline$\$ 25-000-\$ 49,999$ & 43.5 & 26.6 & 46.1 & 40.6 & 30.9 & 44.8 & 41.9 & 39.2 & -3.7 \\
\hline$\$ 50,000-\$ 99,999$ & 41.8 & 48.8 & 63.2 & 50.4 & 54.2 & 65.0 & 55.0 & 54.1 & 31.5 \\
\hline$\$ 100-000-\$ 249,999$ & 60.2 & 66.5 & 78.9 & 61.9 & 69.8 & 67.9 & 74.6 & 68.5 & 23.9 \\
\hline$\$ 250,000-\$ 499,999$ & 86.9 & 99.0 & 147.5 & 112.9 & 130.3 & 108.6 & 120.6 & 115.1 & 38.7 \\
\hline$\$ 500,000-\$ 999,999$ & 200.7 & 242.4 & 176.9 & 234.4 & 244.3 & 203.6 & 165.4 & 209.7 & -17.6 \\
\hline$\$ 1,000,000$ or over & 418.0 & 369.5 & 308.2 & 421.0 & 397.3 & 346.9 & 482.8 & 391.9 & 15.5 \\
\hline Top 1\% of Wealth & 1605.2 & 576.8 & 638.2 & 630.7 & 529.6 & 878.1 & 871.9 & 818.6 & -45.7 \\
\hline C. Race & & & & & & & & & \\
\hline$\overline{\text { Non-Hispanic whites }}$ & 65.2 & 64.0 & 68.0 & 71.2 & 90.7 & 79.8 & 89.7 & 75.5 & 37.7 \\
\hline $\begin{array}{l}\text { Non-Hispanic African- } \\
\text { Americans }\end{array}$ & 50.3 & 46.4 & 45.3 & 56.5 & 61.4 & 67.9 & 79.1 & 58.1 & 57.2 \\
\hline Hispanics $^{a}$ & 16.5 & 7.1 & 49.0 & 120.5 & 31.7 & 33.9 & 97.5 & 50.9 & 491.6 \\
\hline Asian and other races & 65.9 & 53.7 & 196.6 & 96.8 & 62.0 & 22.0 & 121.5 & 88.4 & 84.3 \\
\hline$\underline{\text { D. Age Class }}{ }^{\mathrm{b}}$ & & & & & & & & & \\
\hline Under 35 & 30.8 & 22.6 & 29.6 & 25.4 & 30.9 & 32.6 & 29.7 & 28.8 & -3.5 \\
\hline $35-44$ & 40.6 & 46.2 & 55.3 & 37.2 & 49.8 & 37.0 & 58.4 & 46.4 & 44.0 \\
\hline $45-54$ & 75.6 & 68.2 & 66.4 & 76.8 & 74.4 & 71.3 & 79.3 & 73.1 & 4.8 \\
\hline $55-64$ & 86.9 & 64.2 & 68.0 & 104.2 & 130.3 & 109.8 & 122.0 & 97.9 & 40.4 \\
\hline $65-74$ & 88.9 & 90.4 & 156.7 & 86.4 & 132.4 & 108.6 & 145.6 & 115.6 & 63.7 \\
\hline 75 \& over & 100.3 & 125.6 & 83.3 & 100.8 & 114.0 & 155.1 & 165.4 & 120.6 & 64.9 \\
\hline$\underline{\text { E. Education }^{\text {b }}}$ & & & & & & & & & \\
\hline Less than 12 years & 59.3 & 28.9 & 45.3 & 44.2 & 55.3 & 46.0 & 56.6 & 47.9 & -4.7 \\
\hline 12 years & 40.0 & 50.2 & 46.1 & 56.1 & 62.0 & 54.3 & 69.8 & 54.1 & 74.5 \\
\hline 13-15 years & 69.2 & 70.9 & 79.2 & 70.6 & 81.3 & 56.2 & 74.1 & 71.6 & 7.1 \\
\hline 16 years of more & 105.6 & 97.5 & 89.8 & 100.8 & 124.6 & 133.7 & 136.5 & 112.6 & 29.3 \\
\hline $\begin{array}{l}\text { Note: own computations } \\
\text { Table } 1 \text { for technical det } \\
\text { received up to the time o } \\
\text { a. Hispanics can be of an } \\
\text { b. Households are classif } \\
\text { household. }\end{array}$ & $\begin{array}{l}1989,1 \\
\text { igures } s \\
\text { ey and } \\
\text { ding to }\end{array}$ & $\begin{array}{l}92,19 \\
\text { ow the } \\
\text { cumu } \\
\text { e age }\end{array}$ & $\begin{array}{l}1998, \\
\text { present } \\
\text { ted at }\end{array}$ & $\begin{array}{l}2001, \\
\text { value } \\
\text { a real i } \\
\text { cation }\end{array}$ & $\begin{array}{l}04 \text {, an } \\
\text { all tra } \\
\text { erest } r\end{array}$ & $\begin{array}{l}2007 \\
\text { sfers } \\
\text { e of } 3 \\
\text { of }\end{array}$ & $\begin{array}{l}\text { F. See } \\
\text { of the } \\
\text { percen }\end{array}$ & r reci & $\begin{array}{l}\text { were } \\
\text { lly. }\end{array}$ \\
\hline
\end{tabular}




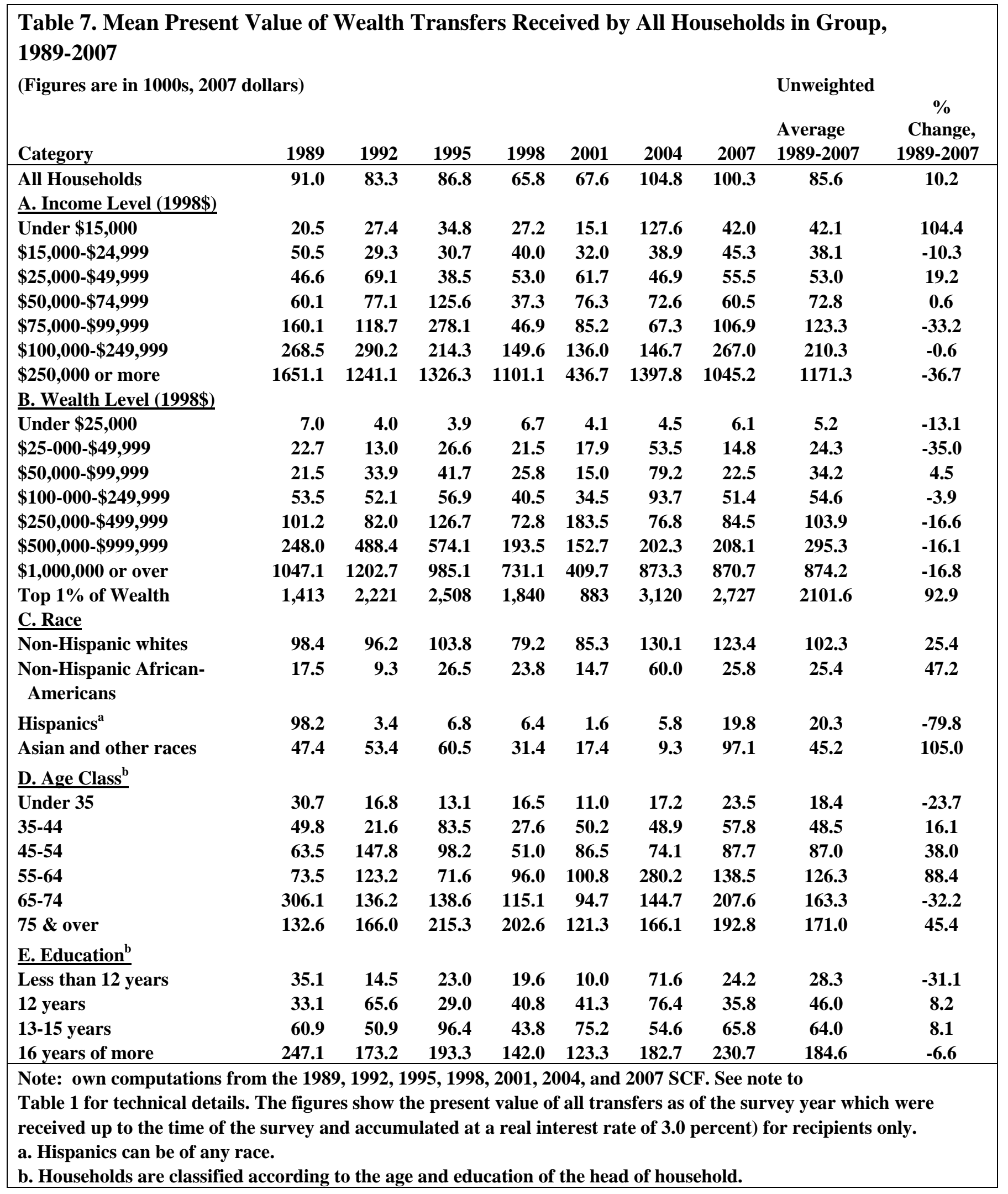




\begin{tabular}{|c|c|c|c|c|c|c|c|c|c|}
\hline \multicolumn{10}{|c|}{ Table 8. Present Value of Wealth Transfers Received as a Percent of Net Worth, } \\
\hline Category & 1989 & 1992 & 1995 & 1998 & 2001 & 2004 & 2007 & $\begin{array}{l}\text { Average } \\
1989-2007\end{array}$ & $\begin{array}{r}\text { Change, } \\
1989-2007 \\
\end{array}$ \\
\hline \multicolumn{10}{|l|}{ A. Income Level (1998\$) } \\
\hline Under $\$ 15,000$ & 54.5 & 57.3 & 54.1 & 44.9 & 26.5 & 180.2 & 42.8 & 65.8 & -11.7 \\
\hline$\$ 15,000-\$ 24,999$ & 35.3 & 27.2 & 30.6 & 35.9 & 27.6 & 33.3 & 36.6 & 32.4 & 1.3 \\
\hline$\$ 25,000-\$ 49,999$ & 26.4 & 41.9 & 26.9 & 33.9 & 33.0 & 25.1 & 28.1 & 30.7 & 1.7 \\
\hline$\$ 50,000-\$ 74,999$ & 22.8 & 31.6 & 47.0 & 13.1 & 22.8 & 21.2 & 16.5 & 25.0 & -6.3 \\
\hline$\$ 75,000-\$ 99,999$ & 29.2 & 24.4 & 63.3 & 11.2 & 16.1 & 16.5 & 19.4 & 25.7 & -9.8 \\
\hline$\$ 100,000-\$ 249,999$ & 26.8 & 26.7 & 19.6 & 13.3 & 12.1 & 14.3 & 19.1 & 18.8 & -7.7 \\
\hline \multicolumn{10}{|l|}{ B. Wealth Level (1998\$) } \\
\hline Under $\$ 25,000$ & -109 & 163.5 & 288.1 & -1014 & 6070 & -297 & -214 & -606.6 & -105.2 \\
\hline$\$ 25-000-\$ 49,999$ & 48.1 & 27.3 & 56.9 & 46.4 & 38.3 & 116.0 & 31.3 & 52.0 & -16.8 \\
\hline$\$ 50,000-\$ 99,999$ & 23.5 & 36.7 & 44.6 & 27.8 & 15.9 & 86.5 & 24.2 & 37.0 & 0.8 \\
\hline$\$ 100-000-\$ 249,999$ & 26.2 & 25.2 & 27.7 & 19.9 & 16.5 & 45.8 & 24.1 & 26.5 & -2.1 \\
\hline$\$ 250,000-\$ 499,999$ & 23.0 & 18.7 & 28.1 & 16.5 & 40.7 & 17.0 & 18.5 & 23.2 & -4.5 \\
\hline$\$ 500,000-\$ 999,999$ & 29.0 & 53.5 & 65.6 & 22.6 & 17.2 & 22.6 & 24.0 & 33.5 & -5.0 \\
\hline$\$ 1,000,000$ or over & 23.6 & 26.4 & 21.4 & 16.5 & 8.9 & 17.8 & 16.1 & 18.7 & -7.5 \\
\hline Top 1\% of Wealth & 22.7 & 27.0 & 23.7 & 17.0 & 5.9 & 19.1 & 14.7 & 18.6 & -8.0 \\
\hline \multicolumn{10}{|l|}{ C. Race } \\
\hline Non-Hispanic whites & 26.1 & 25.3 & 31.5 & 19.4 & 15.7 & 23.5 & 18.9 & 22.9 & -7.2 \\
\hline $\begin{array}{l}\text { Non-Hispanic African- } \\
\text { Americans }\end{array}$ & 27.8 & 13.3 & 47.7 & 32.1 & 19.0 & 61.8 & 21.0 & 31.8 & -6.8 \\
\hline Hispanics $^{\mathrm{a}}$ & 163.7 & 4.0 & 9.8 & 6.3 & 1.7 & 4.9 & 11.6 & 28.9 & -152.1 \\
\hline Asian and other races & 13.4 & 16.2 & 21.1 & 9.7 & 4.1 & 2.6 & 17.6 & 12.1 & 4.2 \\
\hline \multicolumn{10}{|l|}{ D. Age Class ${ }^{\mathrm{b}}$} \\
\hline Under 35 & 36.7 & 26.7 & 30.2 & 21.9 & 12.7 & 28.6 & 25.7 & 26.1 & -10.9 \\
\hline $35-44$ & 20.0 & 9.6 & 46.1 & 11.8 & 17.5 & 17.1 & 18.7 & 20.1 & -1.3 \\
\hline $45-54$ & 14.4 & 32.8 & 25.3 & 11.6 & 15.5 & 14.2 & 13.7 & 18.2 & -0.6 \\
\hline $55-64$ & 14.8 & 21.3 & 14.2 & 14.6 & 12.2 & 33.4 & 15.3 & 18.0 & 0.5 \\
\hline $65-74$ & 62.2 & 27.0 & 29.1 & 20.0 & 12.4 & 19.7 & 20.8 & 27.3 & -41.4 \\
\hline 75 \& over & 32.7 & 43.6 & 58.5 & 52.5 & 22.8 & 29.5 & 31.0 & 38.7 & -1.7 \\
\hline \multicolumn{10}{|l|}{ E. Education $^{b}$} \\
\hline$\overline{\text { Less than } 12 \text { years }}$ & 14.4 & 14.5 & 22.8 & 21.0 & 8.9 & 53.3 & 19.1 & 22.0 & 4.7 \\
\hline 12 years & 21.6 & 37.9 & 17.2 & 21.1 & 20.5 & 40.3 & 14.7 & 24.8 & -6.9 \\
\hline 13-15 years & 25.8 & 19.4 & 41.4 & 16.5 & 25.6 & 19.1 & 20.8 & 24.1 & -5.0 \\
\hline 16 years of more & 37.9 & 26.1 & 33.3 & 19.3 & 12.2 & 19.3 & 19.1 & 23.9 & -18.8 \\
\hline \multicolumn{10}{|c|}{$\begin{array}{l}\text { Note: own computations from the } 1989,1992,1995,1998,2001,2004 \text {, and } 2007 \text { SCF. } \\
\text { The figures show the present value of all wealth transfers as of the survey year which were received } \\
\text { up to the time of the survey and accumulated at a real interest rate of } 3.0 \text { percent as a ratio to net worth } \\
\text { a. Hispanics can be of any race. } \\
\text { b. Households are classified according to the age and education of the head of household. }\end{array}$} \\
\hline
\end{tabular}




\begin{tabular}{|c|c|c|c|c|c|c|c|c|c|c|c|c|c|c|}
\hline \multicolumn{15}{|c|}{$\begin{array}{l}\text { Table 9. Percent of Households Receiving Any Kind of Wealth Transfer } \\
\text { Over Preceding Five and Ten Years Prior to the Survey, 1989-2007 } \\
\text { (Figures are in 1000s, } 2007 \text { dollars) }\end{array}$} \\
\hline Recipients of: & 1989 & 1992 & 1995 & 1998 & 2001 & 2004 & 2007 & 1989 & 1992 & 1995 & 1998 & 2001 & 2004 & 2007 \\
\hline \multicolumn{15}{|l|}{ A. Preceding Five Years } \\
\hline $\begin{array}{l}\text { 1. General wealth transfer } \\
\text { questions }^{\mathrm{a}}\end{array}$ & 7.4 & 6.7 & 5.8 & 8.1 & 4.8 & 4.6 & 8.4 & 125.4 & 109.8 & 153.9 & 108.4 & 151.9 & 208.1 & 159.0 \\
\hline 2. Owner-occupied housing & 0.6 & 0.4 & 0.9 & 0.1 & 0.1 & 0.1 & 0.1 & 84.4 & 91.8 & 56.8 & 96.7 & 373.9 & 373.7 & 97.9 \\
\hline 3. Other real estate & 0.3 & 0.2 & 0.5 & 0.4 & 0.5 & 0.3 & 0.4 & 159.3 & 171.5 & 44.2 & 127.8 & 102.0 & 111.4 & 368.3 \\
\hline 4. Business & 0.0 & 0.0 & 0.0 & 0.0 & 0.0 & 0.0 & 0.0 & 180.5 & -- & 1250.0 & 32.4 & -- & 404.5 & -- \\
\hline 5. Real estate or business & 0.9 & 0.6 & 1.4 & 0.6 & 0.6 & 0.4 & 0.5 & 112.3 & 123.4 & 59.9 & 120.1 & 185.4 & 151.5 & 312.2 \\
\hline \multicolumn{15}{|c|}{ and/or real estate or business ${ }^{b}$} \\
\hline \multicolumn{15}{|l|}{ B. Preceding Ten Years } \\
\hline $\begin{array}{l}\text { 1. General wealth transfer } \\
\text { questions }^{\mathrm{a}}\end{array}$ & 11.9 & 13.0 & 11.7 & 12.3 & 11.0 & 11.4 & 13.2 & 133.8 & 113.7 & 136.0 & 127.4 & 132.3 & 194.8 & 209.1 \\
\hline 2. Owner-occupied housing & 1.3 & 1.0 & 1.5 & 0.3 & 0.3 & 0.3 & 0.3 & 63.1 & 62.4 & 60.1 & 95.9 & 195.8 & 151.4 & 76.9 \\
\hline 3. Other real estate & 0.4 & 0.4 & 0.8 & 0.5 & 0.7 & 0.5 & 0.6 & 152.1 & 121.2 & 107.9 & 132.5 & 154.2 & 170.7 & 339.4 \\
\hline 4. Business & 0.1 & 0.0 & 0.0 & 0.0 & 0.0 & 0.0 & $\mathbf{0 . 0}$ & 106.0 & 443.6 & 875.7 & 32.4 & -- & 87.3 & 99.4 \\
\hline 5. Real estate or business & 1.7 & 1.4 & 2.3 & 0.8 & 1.0 & 0.8 & 0.9 & 87.7 & 83.8 & 81.3 & 117.0 & 194.7 & 159.6 & 255.6 \\
\hline $\begin{array}{l}\text { 6. General wealth transfer } \\
\text { and/or real estate or busi }\end{array}$ & \multicolumn{14}{|c|}{ and/or real estate or business ${ }^{b}$} \\
\hline \multicolumn{15}{|c|}{$\begin{array}{l}\text { Note: own computations from the } 1989,1992,1995,1998,2001,2004 \text {, and } 2007 \text { SCF. In the } 2007 \text { SCF data, the prior five years would be for the period } \\
2003-2007 . \text { The prior ten years would be the period } 1998-2007 . \\
\text { a. Question corresponding to variables X5803, X5808, and X5813. } \\
\text { b. This is the final estimate which includes real estate or business transfers only if no general wealth transfers are reported for those years; } \\
\text { c. The figures are based on the present value of all transfers as of the survey year which were received up } \\
\text { to the time of the survey and accumulated at a real interest rate of } 3.0 \text { percent for recipients only. }\end{array}$} \\
\hline
\end{tabular}




\begin{tabular}{|c|c|c|c|c|}
\hline \multicolumn{5}{|c|}{$\begin{array}{l}\text { Table } 10 \text { Inequality of Wealth Transfers Received, 1989-2007 } \\
\text { [Gini Coefficients] }\end{array}$} \\
\hline Category & 1989 & 1998 & 2007 & $\begin{array}{l}\text { Change, } \\
\text { 1989-2007 }\end{array}$ \\
\hline I. All Households & 0.959 & 0.959 & 0.961 & 0.002 \\
\hline II. Recipients Only & 0.824 & 0.799 & 0.814 & -0.010 \\
\hline \multicolumn{5}{|l|}{ A. Income Level (1998\$) } \\
\hline Under $\$ 25,000$ & 0.730 & 0.730 & 0.760 & 0.030 \\
\hline$\$ 25,000-\$ 74,999$ & 0.740 & 0.746 & 0.742 & 0.002 \\
\hline$\$ 75,000-\$ 99,999$ & 0.808 & 0.663 & 0.747 & -0.061 \\
\hline$\$ 100,000-\$ 249,999$ & 0.790 & 0.769 & 0.813 & 0.023 \\
\hline$\$ 250,000$ or more & 0.837 & 0.897 & 0.829 & -0.008 \\
\hline \multicolumn{5}{|l|}{ B. Race $^{\mathrm{a}}$} \\
\hline Non-Hispanic whites & 0.815 & 0.812 & 0.817 & 0.002 \\
\hline Non-Hispanic African-Americans & 0.744 & 0.729 & 0.754 & 0.010 \\
\hline Hispanics & 0.939 & 0.526 & 0.690 & -0.249 \\
\hline \multicolumn{5}{|l|}{ C. Age Class ${ }^{\mathrm{b}}$} \\
\hline Under 35 & 0.782 & 0.791 & 0.833 & 0.051 \\
\hline $35-44$ & 0.800 & 0.759 & 0.796 & -0.005 \\
\hline $45-54$ & 0.744 & 0.748 & 0.821 & 0.077 \\
\hline $55-64$ & 0.772 & 0.755 & 0.783 & 0.011 \\
\hline $65-74$ & 0.882 & 0.754 & 0.811 & -0.071 \\
\hline 75 \& over & 0.769 & 0.870 & 0.754 & -0.014 \\
\hline \multicolumn{5}{|l|}{$\underline{\text { D. Education }}^{\mathrm{c}}$} \\
\hline Less than 12 years & 0.701 & 0.665 & 0.734 & 0.033 \\
\hline 12 years & 0.762 & 0.777 & 0.709 & -0.053 \\
\hline 13-15 years & 0.779 & 0.730 & 0.773 & -0.006 \\
\hline 16 years of more & 0.850 & 0.835 & 0.824 & -0.026 \\
\hline \multicolumn{5}{|l|}{ Memo: } \\
\hline Correl (NWX,WT) & -0.30 & -0.47 & -0.17 & 0.136 \\
\hline Correl (Y,WT) & 0.122 & 0.046 & 0.074 & -0.048 \\
\hline
\end{tabular}

Note: own computations from the 1989, 1998, and 2007 SCF.

The figures are based on the present value of all wealth transfers as of the survey year which were received up to the time of the survey and accumulated at a real interest rate of 3.0 percent. Except for the first

line, the Gini coefficients are for recipients only. Key:

NWX = Total net worth excluding wealth transfers

$\mathrm{WT}=$ Wealth transfers

$Y=$ (Current) Household income

a. Hispanics can be of any race. The category "Asians and others' is excluded because of its small sample size.

b. Households are classified according to the age of the head of household.

c. Households are classified according to the education of the head of household. 


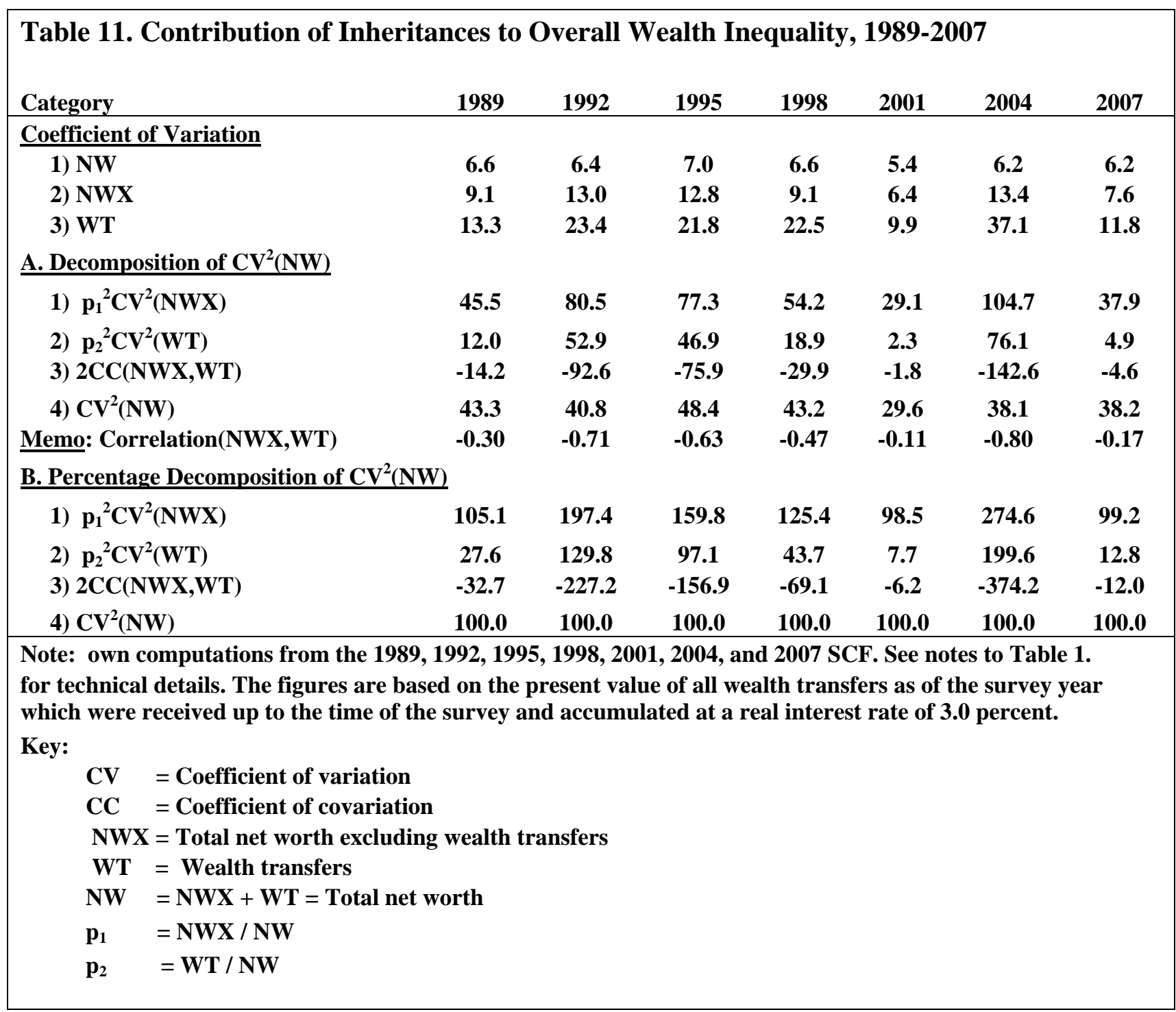




\begin{tabular}{|c|c|c|c|}
\hline \multicolumn{4}{|c|}{$\begin{array}{l}\text { Table } 12 \text { Receipt of Inheritances in Preceding Calendar Year } \\
\text { (Dollar figures are in 1000s, } 2007 \text { dollars) }\end{array}$} \\
\hline Survey Year & Percentage & $\begin{array}{l}\text { Mean } \\
\text { (Recipients } \\
\text { Only) }\end{array}$ & $\begin{array}{l}\text { Median } \\
\text { (Recipients } \\
\text { Only) }\end{array}$ \\
\hline 1988 & 1.9 & 30.4 & 14.6 \\
\hline 1989 & 2.3 & 57.4 & 17.5 \\
\hline 1990 & 1.7 & 49.2 & 16.7 \\
\hline 1991 & 2.2 & 37.4 & 15.9 \\
\hline 1992 & 1.6 & 51.6 & 15.2 \\
\hline 1993 & 1.4 & 61.0 & 14.8 \\
\hline 1994 & 1.0 & 32.3 & 10.0 \\
\hline 1995 & 1.5 & 42.5 & 14.0 \\
\hline 1996 & 1.5 & 34.6 & 17.0 \\
\hline 1997 & 1.8 & 51.4 & 13.2 \\
\hline 1999 & 1.7 & 63.4 & 25.8 \\
\hline 2001 & 2.0 & 41.5 & 22.4 \\
\hline 2003 & 2.1 & 73.6 & 19.9 \\
\hline 2005 & 2.1 & 53.9 & 17.0 \\
\hline 2007 & 1.9 & 60.4 & 21.2 \\
\hline
\end{tabular}




\begin{tabular}{|c|c|c|c|c|}
\hline \multicolumn{5}{|c|}{$\begin{array}{l}\text { Table } 13 \text { Receipt of Inheritances (M } \\
\text { 1987-2006 } \\
\text { (Dollar figures are in 1000s, } 2007 \text { dollars) }\end{array}$} \\
\hline Category & Percentage & $\begin{array}{l}\text { Mean } \\
\text { (Recipients } \\
\text { Only) } \\
\end{array}$ & $\begin{array}{l}\text { Median } \\
\text { (Recipients } \\
\text { Only) } \\
\end{array}$ & $\begin{array}{l}\text { Mean } \\
\text { (All Households } \\
\text { in Group) }\end{array}$ \\
\hline All Families & 1.8 & 50.7 & 16.7 & 0.9 \\
\hline \multicolumn{5}{|c|}{ A. Income Level (1998\$) } \\
\hline Under $\$ 15,000$ & 1.0 & 22.3 & 10.6 & 0.2 \\
\hline$\$ 15,000-\$ 24,999$ & 1.5 & 22.7 & 11.4 & 0.3 \\
\hline$\$ 25,000-\$ 49,999$ & 1.6 & 45.2 & 13.6 & 0.7 \\
\hline$\$ 50,000-\$ 74,999$ & 2.1 & 51.3 & 20.1 & 1.1 \\
\hline$\$ 75,000-\$ 99,999$ & 2.6 & 69.8 & 23.4 & 1.8 \\
\hline$\$ 100,000-\$ 249,999$ & 2.8 & 69.7 & 27.4 & 2.0 \\
\hline$\$ 250,000$ or more & 3.8 & 143.2 & 57.4 & 5.4 \\
\hline \multicolumn{5}{|l|}{ B. Race $^{\mathrm{a}}$} \\
\hline White & 2.0 & 51.8 & 17.1 & 1.0 \\
\hline African American & 0.5 & 21.1 & 6.5 & 0.1 \\
\hline \multicolumn{5}{|l|}{$\underline{\text { C. Age Class }}{ }^{\mathrm{a}}$} \\
\hline Under 35 & 1.1 & 24.4 & 7.6 & 0.3 \\
\hline $35-44$ & 1.4 & 47.7 & 15.2 & 0.7 \\
\hline $45-54$ & 2.5 & 53.4 & 18.7 & 1.3 \\
\hline $55-64$ & 2.9 & 67.3 & 21.2 & 2.0 \\
\hline $65-74$ & 2.1 & 57.9 & 24.9 & 1.2 \\
\hline 75 \& over & 1.5 & 44.4 & 18.3 & 0.7 \\
\hline \multicolumn{5}{|l|}{$\underline{\text { D. Education }}^{\mathrm{a}}$} \\
\hline Less than 12 years & 0.9 & 25.6 & 9.0 & 0.2 \\
\hline 12 years & 1.6 & 38.4 & 13.2 & 0.6 \\
\hline 13-15 years & 2.1 & 53.5 & 15.9 & 1.1 \\
\hline 16 years of more & 2.5 & 65.7 & 25.8 & 1.6 \\
\hline $\begin{array}{l}\text { Note: Own comput } \\
\text { a. Families are clas } \\
\text { Education levels ar }\end{array}$ & $\begin{array}{l}\text { ions from } 19 \\
\text { ied accordin } \\
\text { nissing for sc }\end{array}$ & $\begin{array}{l}87-1997,199 \\
\text { g to the race, } \\
\text { ome heads. }\end{array}$ & $\begin{array}{l}2001,2003,2 \\
\text { ge and educat }\end{array}$ & $\begin{array}{l}\text { 05, and } 2007 \text { PSID. } \\
\text { on of the head of the family. }\end{array}$ \\
\hline
\end{tabular}




\section{Table 14 Percent of Families Receiving an Inheritance and Mean and Median}

Values, 1984-2007

(Dollar figures are in 1000s, 2007 dollars)

\begin{tabular}{|c|c|c|c|c|c|c|c|}
\hline \multicolumn{8}{|c|}{ Survey Year } \\
\hline $1984^{a}$ & $1989^{b}$ & $1994^{b}$ & $1999^{b}$ & $2001^{c}$ & $2003^{c}$ & $2005^{\mathrm{c}}$ & $2007^{c}$ \\
\hline \multicolumn{8}{|c|}{ A. Percent of Families Indicating an Inheritance } \\
\hline 19.2 & 5.7 & 5.9 & 7.6 & 4.4 & 4.5 & 4.5 & 4.6 \\
\hline \multicolumn{8}{|c|}{ B. Mean Present Value of Inheritance for Recipients Only ${ }^{d}$} \\
\hline 193.5 & 144.8 & 125.8 & 99.0 & 76.4 & 103.5 & 97.1 & 94.0 \\
\hline \multicolumn{8}{|c|}{ C. Median Present Value of Inheritance for Recipients Only ${ }^{d}$} \\
\hline 42.9 & 54.2 & 47.1 & 40.6 & 34.0 & 39.4 & 35.9 & 33.8 \\
\hline \multicolumn{8}{|c|}{$\begin{array}{l}\text { Note: own computations from the } 1984,1989,1994,1999,2001,2003,2005 \text {, and } 2007 \text { PSID. } \\
\text { a. Retrospective period is complete and there is no minimum inheritance. } \\
\text { b. Retrospective period is five years and minimum inheritance is } \$ 10,000 \text {. } \\
\text { c. Retrospective period is two years and minimum inheritance is } \$ 10,000 \text {. } \\
\text { d. The figures are based on the present value of all inheritances as of the survey year which were } \\
\text { received up to the time of the survey and accumulated at a real interest rate of } 3.0 \text { percent for } \\
\text { recipients only. In some cases, data on amount and year may be missing. }\end{array}$} \\
\hline
\end{tabular}




\begin{tabular}{|c|c|c|c|c|c|c|c|c|}
\hline \multicolumn{9}{|c|}{ (Dollar figures are in 1000s, 2007 dollars) } \\
\hline Category & $1984^{\mathrm{a}}$ & $1989^{b}$ & $1994^{\mathrm{b}}$ & $1999^{b}$ & $2001^{c}$ & $2003^{\mathrm{c}}$ & $2005^{c}$ & $2007^{c}$ \\
\hline All Families & 193.5 & 144.8 & 125.8 & 99.0 & 76.4 & 103.5 & 97.1 & 94.0 \\
\hline \multicolumn{9}{|c|}{ A. Income Level (1998\$) } \\
\hline Under $\$ 15,000$ & 111.8 & 77.2 & 53.9 & 70.2 & 74.7 & 39.5 & 36.9 & 51.0 \\
\hline$\$ 15,000-\$ 24,999$ & 97.7 & 63.7 & 58.4 & 176.5 & 82.8 & 22.9 & 163.8 & 63.3 \\
\hline$\$ 25,000-\$ 49,999$ & 147.2 & 100.1 & 168.1 & 73.8 & 79.9 & 111.0 & 85.4 & 96.4 \\
\hline$\$ 50,000-\$ 74,999$ & 379.8 & 151.2 & 100.1 & 75.0 & 47.5 & 90.3 & 80.2 & 91.5 \\
\hline$\$ 75,000-\$ 99,999$ & 138.2 & 157.9 & 133.0 & 92.5 & 108.8 & 83.2 & 102.8 & 104.9 \\
\hline$\$ 100,000-\$ 249,999$ & 185.4 & 246.1 & 166.8 & 137.8 & 75.9 & 127.3 & 101.0 & 119.8 \\
\hline$\$ 250,000$ or more & 79.7 & 307.4 & 124.5 & 31.2 & 39.0 & 332.5 & 83.5 & 156.4 \\
\hline \multicolumn{9}{|c|}{ B. Wealth Level (1998\$) } \\
\hline Under $\$ 25,000$ & 43.9 & 48.3 & 39.6 & $\mathbf{8 8 . 0}$ & 27.7 & 26.9 & 34.5 & 34.6 \\
\hline$\$ 25-000-\$ 49,999$ & 46.4 & 38.4 & 44.0 & 43.0 & 67.6 & 39.7 & 26.9 & 28.9 \\
\hline$\$ 50,000-\$ 99,999$ & 73.7 & 66.8 & 56.2 & 43.4 & 49.2 & 39.7 & 54.9 & 53.7 \\
\hline$\$ 100-000-\$ 249,999$ & 135.7 & 83.1 & 68.6 & 73.5 & 76.6 & 64.6 & 69.8 & 60.4 \\
\hline$\$ 250,000-\$ 499,999$ & 254.5 & 95.0 & 167.9 & 111.1 & 94.5 & 109.6 & 72.7 & 76.7 \\
\hline$\$ 500,000-\$ 999,999$ & 262.1 & 210.0 & 278.7 & 153.3 & 121.7 & 232.8 & 125.7 & 167.0 \\
\hline$\$ 1,000,000$ or over & 2707.2 & 768.2 & 324.9 & 168.5 & 89.6 & 298.2 & 350.4 & 266.4 \\
\hline \multicolumn{9}{|l|}{$\underline{\text { C. Race }}{ }^{\mathrm{d}}$} \\
\hline White & 197.8 & 147.0 & 128.8 & 100.1 & 77.2 & 105.6 & 99.8 & 95.8 \\
\hline African American & 72.8 & 52.4 & 44.3 & 66.3 & 59.4 & 51.4 & 35.7 & 50.9 \\
\hline \multicolumn{9}{|l|}{$\underline{\text { D. Age Class }}{ }^{\mathrm{e}}$} \\
\hline Under 35 & 52.4 & 75.3 & 58.2 & 108.2 & 63.7 & 43.7 & 53.2 & 57.3 \\
\hline $35-44$ & 106.6 & 154.3 & 90.0 & 86.8 & 62.2 & 85.3 & 65.5 & 89.4 \\
\hline $45-54$ & 151.5 & 229.5 & 72.5 & 106.5 & 77.7 & 135.4 & 82.2 & 78.3 \\
\hline $55-64$ & 174.7 & 193.4 & 225.9 & 68.6 & 73.1 & 110.9 & 90.9 & 150.2 \\
\hline $65-74$ & 192.5 & 100.3 & 251.9 & 131.8 & 114.7 & 233.7 & 146.3 & 63.7 \\
\hline 75 \& over & 568.0 & 89.2 & 193.6 & 95.7 & 120.2 & 58.7 & 303.7 & 146.8 \\
\hline \multicolumn{9}{|l|}{$\underline{\text { E. Education }}^{\mathrm{f}}$} \\
\hline Less than 12 years & 87.9 & 94.4 & 83.5 & 162.1 & 59.9 & 164.2 & 35.9 & 75.1 \\
\hline 12 years & 115.0 & 81.9 & 141.7 & 108.6 & 106.3 & 59.0 & 87.9 & 75.3 \\
\hline 13-15 years & 137.1 & 155.5 & 104.5 & 67.6 & 74.8 & 99.3 & 84.4 & 90.9 \\
\hline 16 years of more & 404.3 & 191.6 & 139.2 & 97.1 & 64.3 & 105.3 & 118.0 & 120.6 \\
\hline \multicolumn{9}{|c|}{$\begin{array}{l}\text { Note: own computations from the } 1984,1989,1994,1999,2001,2003,2005 \text {, and } 2007 \text { PSID. } \\
\text { The figures are based on the present value of all inheritances as of the survey year which were received up to } \\
\text { the time of the survey and accumulated at a real interest rate of } 3.0 \text { percent for recipients only. } \\
\text { a. Retrospective period is complete and there is no minimum inheritance. } \\
\text { b. Retrospective period is five years and minimum inheritance is } \$ 10,000 \text {. } \\
\text { c. Retrospective period is two years and minimum inheritance is } \$ 10,000 \text {. } \\
\text { d. In } 1984 \text {, race is for family and is taken from } 1972 \text { interview. In other years, it is the race of the head. } \\
\text { e. Families are classified according to the age of the head of the family } \\
\text { f. Families are classified according to the education of the head of the family, which is missing for some } \\
\text { families. }\end{array}$} \\
\hline
\end{tabular}




\begin{tabular}{|c|c|c|c|c|c|c|c|c|}
\hline \multicolumn{9}{|c|}{$\begin{array}{l}\text { Table } 17 \text { Median Present Value of Inherit } \\
\text { (Dollar figures are in 1000s, } 2007 \text { dollars) }\end{array}$} \\
\hline Category & $1984^{\mathrm{a}}$ & $1989^{b}$ & $1994^{b}$ & $1999^{b}$ & $2001^{c}$ & $2003^{c}$ & $2005^{c}$ & $2007^{c}$ \\
\hline All Families & 42.9 & 54.2 & 47.1 & 40.6 & 34.0 & 39.4 & 35.9 & 33.8 \\
\hline \multicolumn{9}{|c|}{ A. Income Level (1998\$) } \\
\hline Under \$15,000 & 38.2 & 58.1 & 31.4 & 59.0 & 30.4 & 24.9 & 26.5 & 53.0 \\
\hline$\$ 15,000-\$ 24,999$ & 26.6 & 41.3 & 27.2 & 53.7 & 51.2 & 18.4 & 26.5 & 41.5 \\
\hline$\$ 25,000-\$ 49,999$ & 38.0 & 54.2 & 53.4 & 34.2 & 46.3 & 43.9 & 43.0 & 22.5 \\
\hline$\$ 50,000-\$ 74,999$ & 50.5 & 54.2 & 36.6 & 36.7 & 28.2 & 35.6 & 23.3 & 22.5 \\
\hline$\$ 75,000-\$ 99,999$ & 56.7 & 45.2 & 53.7 & 31.5 & 52.9 & 35.0 & 35.9 & 42.4 \\
\hline$\$ 100,000-\$ 249,999$ & 81.2 & 86.9 & 37.0 & 57.8 & 31.0 & 42.8 & 49.1 & 33.8 \\
\hline$\$ 250,000$ or more & 63.6 & 52.4 & 59.1 & 26.2 & 14.9 & 415.7 & 83.8 & 135.3 \\
\hline \multicolumn{9}{|c|}{ B. Wealth Level (1998\$) } \\
\hline Under \$25,000 & 17.5 & 31.0 & 26.7 & 16.3 & 24.6 & 17.4 & 16.8 & 20.0 \\
\hline$\$ 25-000-\$ 49,999$ & 17.5 & 37.3 & 31.4 & 27.4 & 23.4 & 31.1 & 23.9 & 21.0 \\
\hline$\$ 50,000-\$ 99,999$ & 44.2 & 48.5 & 38.9 & 36.1 & 46.3 & 27.3 & 40.7 & 33.8 \\
\hline$\$ 100-000-\$ 249,999$ & 40.4 & 45.2 & 44.4 & 40.6 & 34.0 & 48.6 & 33.5 & 28.2 \\
\hline$\$ 250,000-\$ 499,999$ & 105.5 & 72.2 & 53.3 & 54.9 & 49.6 & 43.9 & 45.2 & 45.1 \\
\hline$\$ 500,000-\$ 999,999$ & 128.7 & 124.6 & 75.0 & 96.9 & 86.9 & 89.0 & 39.6 & 95.4 \\
\hline$\$ 1,000,000$ or over & 112.4 & 678.3 & 71.5 & 123.5 & 39.6 & 178.1 & 167.5 & 94.7 \\
\hline \multicolumn{9}{|l|}{$\underline{\text { C. } \text { Race }^{\mathrm{d}}}$} \\
\hline White & 43.9 & 54.2 & 47.1 & 39.3 & 32.1 & 37.3 & 35.9 & 33.9 \\
\hline African American & 32.5 & 29.1 & 25.0 & 61.7 & 62.0 & 39.4 & 21.2 & 21.2 \\
\hline \multicolumn{9}{|l|}{$\underline{\text { D. Age Class }}{ }^{\mathrm{e}}$} \\
\hline Under 35 & 14.6 & 33.4 & 26.7 & 23.0 & 23.4 & 23.8 & 18.0 & 21.4 \\
\hline $35-44$ & 32.5 & 45.2 & 50.0 & 37.3 & 26.4 & 31.1 & 23.8 & 30.0 \\
\hline $45-54$ & 56.7 & 86.9 & 48.3 & 52.4 & 39.7 & 49.7 & 28.9 & 45.1 \\
\hline $55-64$ & 40.7 & 77.5 & 51.6 & 36.1 & 45.9 & 48.6 & 45.2 & 50.7 \\
\hline $65-74$ & 85.2 & 46.4 & 62.8 & 98.3 & 124.1 & 178.1 & 90.5 & 42.4 \\
\hline 75 \& over & 65.1 & 90.3 & 37.6 & 68.6 & 24.6 & 30.9 & 59.8 & 113.3 \\
\hline \multicolumn{9}{|l|}{$\underline{\text { E. Education }}^{\mathrm{f}}$} \\
\hline Less than 12 years & 30.0 & 58.1 & 49.5 & 42.5 & 45.9 & 30.6 & 28.9 & 45.1 \\
\hline 12 years & 37.6 & 52.1 & 44.4 & 41.2 & 47.1 & 19.0 & 37.0 & 33.8 \\
\hline 13-15 years & 50.9 & 46.5 & 53.3 & 37.6 & 30.4 & 45.1 & 28.3 & 42.4 \\
\hline 16 years of more & 69.8 & 54.3 & 47.1 & 42.0 & 27.8 & 48.6 & 39.3 & 32.9 \\
\hline \multicolumn{9}{|c|}{$\begin{array}{l}\text { Note: own computations from the } 1984,1989,1994,1999,2001,2003,2005 \text {, and } 2007 \text { PSID. } \\
\text { The figures are based on the present value of all inheritances as of the survey year which were received up to } \\
\text { the time of the survey and accumulated at a real interest rate of } 3.0 \text { percent for recipients only. } \\
\text { a. Retrospective period is complete and there is no minimum inheritance. } \\
\text { b. Retrospective period is five years and minimum inheritance is } \$ 10,000 \text {. } \\
\text { c. Retrospective period is two years and minimum inheritance is } \$ 10,000 \text {. } \\
\text { d. In } 1984 \text {, race is for family and is taken from } 1972 \text { interview. In other years, it is the race of the head. } \\
\text { e. Families are classified according to the age of the head of the family } \\
\text { f. Families are classified according to the education of the head of the family, which is missing for some } \\
\text { families. }\end{array}$} \\
\hline
\end{tabular}




\begin{tabular}{|c|c|c|c|c|c|c|c|c|}
\hline \multicolumn{9}{|c|}{ (Dollar figures are in 1000s, 2007 dollars) } \\
\hline Category & $1984^{\mathrm{a}}$ & $1989^{b}$ & $1994^{\mathrm{b}}$ & $1999^{b}$ & $2001^{c}$ & $2003^{c}$ & $2005^{c}$ & $2007^{c}$ \\
\hline All Families & 37.2 & 8.3 & 7.4 & 7.5 & 3.4 & 4.7 & 4.4 & 4.3 \\
\hline \multicolumn{9}{|c|}{ A. Income Level (1998\$) } \\
\hline Under $\$ 15,000$ & 15.0 & 2.1 & 1.5 & 1.8 & 1.9 & 0.8 & 0.6 & 1.6 \\
\hline$\$ 15,000-\$ 24,999$ & 14.7 & 2.3 & 1.8 & 7.9 & 2.3 & 0.4 & 7.4 & 2.0 \\
\hline$\$ 25,000-\$ 49,999$ & 28.3 & 4.6 & 8.6 & 4.9 & 2.7 & 4.0 & 3.2 & 3.7 \\
\hline$\$ 50,000-\$ 74,999$ & 88.1 & 11.6 & 6.9 & 6.8 & 2.2 & 4.7 & 4.6 & 5.3 \\
\hline$\$ 75,000-\$ 99,999$ & 32.6 & 12.0 & 13.6 & 10.7 & 7.7 & 6.3 & 7.0 & 6.5 \\
\hline$\$ 100,000-\$ 249,999$ & 56.7 & 28.1 & 21.5 & 22.0 & 7.0 & 12.0 & 7.6 & 8.7 \\
\hline$\$ 250,000$ or more & 11.9 & 62.7 & 27.4 & 2.7 & 1.6 & 35.6 & 2.8 & 10.6 \\
\hline \multicolumn{9}{|c|}{ B. Wealth Level (1998\$) } \\
\hline Under $\$ 25,000$ & 3.2 & 0.8 & 1.0 & 2.2 & 0.5 & 0.5 & 0.7 & 0.6 \\
\hline$\$ 25-000-\$ 49,999$ & 6.8 & 1.1 & 1.5 & 3.2 & 1.5 & 1.3 & 1.0 & 1.4 \\
\hline$\$ 50,000-\$ 99,999$ & 14.0 & 3.3 & 3.1 & 2.2 & 2.2 & 1.7 & 2.1 & 2.1 \\
\hline$\$ 100-000-\$ 249,999$ & 40.0 & 6.6 & 4.7 & 7.6 & 3.9 & 3.8 & 4.0 & 3.4 \\
\hline$\$ 250,000-\$ 499,999$ & 100.5 & 11.4 & 22.7 & 13.9 & 8.0 & 8.2 & 4.5 & 6.0 \\
\hline$\$ 500,000-\$ 999,999$ & 139.2 & 42.8 & 44.0 & 31.9 & 11.6 & 21.2 & 14.2 & 14.0 \\
\hline$\$ 1,000,000$ or over & 812.2 & 139.0 & 49.4 & 37.9 & 11.7 & 28.6 & 30.1 & 22.6 \\
\hline \multicolumn{9}{|l|}{ C. Race $^{\mathrm{d}}$} \\
\hline White & 41.7 & 9.4 & 8.5 & 8.5 & 3.8 & 5.3 & 5.0 & 4.9 \\
\hline African American & 4.5 & 0.5 & 0.7 & 1.2 & 1.0 & 0.7 & 0.6 & 0.7 \\
\hline \multicolumn{9}{|l|}{$\underline{\text { D. Age Class }}^{\mathrm{e}}$} \\
\hline Under 35 & 4.5 & 3.5 & 2.4 & 5.4 & 2.7 & 1.6 & 2.2 & 2.2 \\
\hline $35-44$ & 16.6 & 7.9 & 5.3 & 5.7 & 2.1 & 4.2 & 2.2 & 3.9 \\
\hline $45-54$ & 30.8 & 18.6 & 6.2 & 12.7 & 4.8 & 7.3 & 3.9 & 4.1 \\
\hline $55-64$ & 54.9 & 15.5 & 15.4 & 7.1 & 4.4 & 8.5 & 7.0 & 9.8 \\
\hline $65-74$ & 60.3 & 4.9 & 18.6 & 10.0 & 4.8 & 5.6 & 5.4 & 3.1 \\
\hline 75 \& over & 182.9 & 4.2 & 5.8 & 4.2 & 1.9 & 1.0 & 9.4 & 2.8 \\
\hline \multicolumn{9}{|l|}{$\underline{\text { E. Education }}{ }^{\mathrm{f}}$} \\
\hline Less than 12 years & 13.3 & 2.4 & 2.6 & 7.5 & 1.0 & 1.8 & 0.5 & 1.9 \\
\hline 12 years & 19.1 & 3.6 & 7.4 & 5.3 & 3.1 & 1.7 & 3.0 & 2.9 \\
\hline $13-15$ years & 30.3 & 10.1 & 5.0 & 5.1 & 3.7 & 5.2 & 4.4 & 5.0 \\
\hline 16 years of more & 112.4 & 20.7 & 14.6 & 13.4 & 5.3 & 8.5 & 8.6 & 7.2 \\
\hline \multicolumn{9}{|c|}{$\begin{array}{l}\text { Note: own computations from the } 1984,1989,1994,1999,2001,2003,2005 \text {, and } 2007 \text { PSID. } \\
\text { The figures are based on the present value of all inheritances as of the survey year which were received up to } \\
\text { the time of the survey and accumulated at a real interest rate of } 3.0 \text { percent for recipients only. } \\
\text { a. Retrospective period is complete and there is no minimum inheritance. } \\
\text { b. Retrospective period is five years and minimum inheritance is } \$ 10,000 \text {. } \\
\text { c. Retrospective period is two years and minimum inheritance is } \$ 10,000 \text {. } \\
\text { d. In } 1984 \text {, race is for family and is taken from } 1972 \text { interview. In other years, it is the race of the head. } \\
\text { e. Families are classified according to the age of the head of the family } \\
\text { f. Families are classified according to the education of the head of the family, which is missing for some } \\
\text { families. }\end{array}$} \\
\hline
\end{tabular}




\begin{tabular}{|c|c|c|c|c|c|c|c|c|c|}
\hline \multirow[b]{2}{*}{ Category } & \multicolumn{3}{|c|}{$\begin{array}{l}\text { Percent Receiving } \\
\text { A Wealth Transfer }\end{array}$} & \multicolumn{3}{|c|}{$\begin{array}{l}\text { Mean Value of Transfers } \\
\text { Among Recipients [2007\$] }\end{array}$} & \multicolumn{3}{|c|}{$\begin{array}{l}\text { Median Value of Transfers } \\
\text { Among Recipients [2007\$] }\end{array}$} \\
\hline & 1989 & 1995 & 1998 & 1989 & 1995 & 1998 & 1989 & 1995 & 1998 \\
\hline $\begin{array}{l}\text { All Households } \\
\text { A. Income Level (1998\$) }\end{array}$ & 5.3 & 3.4 & 6.0 & 250.5 & 354.7 & 181.0 & 86.9 & 44.0 & 64.2 \\
\hline Under \$15,000 & 3.3 & 1.6 & 3.3 & 177.5 & 53.4 & 98.6 & 65.2 & 36.7 & 32.1 \\
\hline$\$ 15,000-\$ 24,999$ & 3.8 & 2.7 & 5.5 & 202.7 & 43.3 & 133.9 & 84.7 & 29.3 & 46.5 \\
\hline$\$ 25,000-\$ 49,999$ & 5.7 & 2.8 & 5.4 & 149.5 & 64.4 & 105.1 & 73.9 & 29.3 & 43.3 \\
\hline$\$ 50,000-\$ 74,999$ & 5.6 & 3.6 & 7.2 & 251.3 & 1680.0 & 126.4 & 86.9 & 58.7 & 80.2 \\
\hline$\$ 75,000-\$ 99,999$ & 9.5 & 6.7 & 8.1 & 204.1 & 75.7 & 161.4 & 65.2 & 44.0 & 61.0 \\
\hline$\$ 100,000-\$ 249,999$ & 8.7 & 10.0 & 11.8 & 554.4 & 195.3 & 355.8 & 187.3 & 58.7 & 80.2 \\
\hline$\$ 250,000$ or more & 9.4 & 11.6 & 11.8 & 972.1 & 683.3 & 993.2 & 130.4 & 110.0 & 320.9 \\
\hline \multicolumn{10}{|l|}{ B. Wealth Level (1998\$) } \\
\hline Under \$25,000 & 1.0 & 1.2 & 3.0 & 226.7 & 33.9 & 63.7 & 41.8 & 24.9 & 44.9 \\
\hline$\$ 25-000-\$ 49,999$ & 4.2 & 3.1 & 3.6 & 62.9 & 89.2 & 63.6 & 36.8 & 22.0 & 24.1 \\
\hline$\$ 50,000-\$ 99,999$ & 5.6 & 3.2 & 5.7 & 94.6 & 54.4 & 49.0 & 92.0 & 44.0 & 28.9 \\
\hline$\$ 100-000-\$ 249,999$ & 9.5 & 4.8 & 7.0 & 172.6 & 61.6 & 75.8 & 70.2 & 35.2 & 40.1 \\
\hline$\$ 250,000-\$ 499,999$ & 10.1 & 6.8 & 10.0 & 212.5 & 138.9 & 176.5 & 86.9 & 73.3 & 112.3 \\
\hline$\$ 500,000-\$ 999,999$ & 13.1 & 8.1 & 11.8 & 241.0 & 2586.4 & 236.2 & 133.8 & 102.7 & 160.5 \\
\hline$\$ 1,000,000$ or over & 18.9 & 10.0 & 17.1 & 382.8 & 432.4 & 688.1 & 200.7 & 132.0 & 256.4 \\
\hline \multicolumn{10}{|l|}{ C. Race } \\
\hline White & 5.7 & 3.5 & 6.5 & 251.1 & 384.4 & 178.5 & 84.1 & 44.1 & 66.4 \\
\hline African American & 2.6 & 2.4 & 2.6 & 240.8 & 59.1 & 227.6 & 73.9 & 29.3 & 27.3 \\
\hline \multicolumn{10}{|l|}{ D. Age Class ${ }^{\mathrm{b}}$} \\
\hline Under 35 & 5.8 & 3.3 & 5.1 & 185.1 & 75.1 & 111.1 & 65.2 & 44.0 & 49.7 \\
\hline $35-44$ & 4.5 & 4.2 & 5.5 & 395.0 & 125.3 & 144.0 & 45.6 & 49.9 & 40.1 \\
\hline $45-54$ & 4.3 & 4.1 & 6.2 & 196.2 & 1237.5 & 271.1 & 86.9 & 58.7 & 72.2 \\
\hline $55-64$ & 7.8 & 3.1 & 9.8 & 213.6 & 94.8 & 166.2 & 102.1 & 73.3 & 72.2 \\
\hline $65-74$ & 5.7 & 1.1 & 6.9 & 311.1 & 343.7 & 226.7 & 107.5 & 35.2 & 112.3 \\
\hline 75 \& over & 3.0 & 3.2 & 3.3 & 231.1 & 41.1 & 202.1 & 43.5 & 29.3 & 32.1 \\
\hline \multicolumn{10}{|l|}{ E. Education ${ }^{\text {b }}$} \\
\hline$\overline{\text { Less than } 12 \text { years }}$ & 3.1 & 1.2 & 2.3 & 170.4 & 47.6 & 43.9 & 89.1 & 29.3 & 20.9 \\
\hline 12 years & 3.6 & 2.9 & 3.8 & 237.0 & 72.0 & 125.2 & 63.0 & 41.1 & 35.3 \\
\hline $13-15$ years & 6.3 & 2.7 & 7.9 & 223.1 & 107.3 & 164.6 & 71.7 & 58.7 & 64.2 \\
\hline 16 years of more & 9.1 & 6.2 & 9.2 & 303.2 & 643.6 & 240.3 & 95.3 & 48.4 & 89.9 \\
\hline
\end{tabular}




\begin{tabular}{|c|c|c|}
\hline \multicolumn{3}{|c|}{$\begin{array}{l}\text { Table } 20 \text { Mean and Median Present Value of Inheritances Received among Recipients, 1984-2007 } \\
\text { Dollar figures are in 1000s, } 2007 \text { dollars) }\end{array}$} \\
\hline Category & Mean & Median \\
\hline All families & 120.8 & 37.3 \\
\hline \multicolumn{3}{|c|}{ A. Income Level (1998\$) } \\
\hline Under \$15,000 & 70.0 & 32.5 \\
\hline$\$ 15,000-\$ 24,999$ & 93.1 & 28.4 \\
\hline$\$ 25,000-\$ 49,999$ & 112.6 & 38.1 \\
\hline$\$ 50,000-\$ 74,999$ & 158.7 & 36.7 \\
\hline$\$ 75,000-\$ 99,999$ & 106.6 & 39.3 \\
\hline$\$ 100,000-\$ 249,999$ & 133.6 & 49.1 \\
\hline$\$ 250,000$ or more & 157.7 & 66.6 \\
\hline \multicolumn{3}{|c|}{ B. Wealth Level (1998\$) } \\
\hline Under \$25,000 & 42.0 & 18.6 \\
\hline$\$ 25-000-\$ 49,999$ & 39.3 & 23.0 \\
\hline$\$ 50,000-\$ 99,999$ & 55.9 & 37.3 \\
\hline$\$ 100-000-\$ 249,999$ & 84.3 & 36.1 \\
\hline$\$ 250,000-\$ 499,999$ & 128.2 & 50.8 \\
\hline$\$ 500,000-\$ 999,999$ & 192.4 & 78.5 \\
\hline$\$ 1,000,000$ or over & 427.2 & 81.3 \\
\hline \multicolumn{3}{|l|}{ C. Race $^{\mathrm{a}}$} \\
\hline White & 123.1 & 37.4 \\
\hline African American & 54.2 & 34.9 \\
\hline \multicolumn{3}{|l|}{ D. Age Class } \\
\hline Under 35 & 60.6 & 21.7 \\
\hline $35-44$ & 87.2 & 32.8 \\
\hline $45-54$ & 104.9 & 45.2 \\
\hline $55-64$ & 126.7 & 40.7 \\
\hline $65-74$ & 152.2 & 62.8 \\
\hline 75 \& over & 351.2 & 51.5 \\
\hline \multicolumn{3}{|l|}{ E. Education ${ }^{c}$} \\
\hline Less than 12 years & 91.0 & 33.2 \\
\hline 12 years & 96.9 & 37.2 \\
\hline 13-15 years & 96.1 & 38.3 \\
\hline 16 years of more & 159.3 & 41.1 \\
\hline
\end{tabular}


Calculations are based on a pooled sample in which the unit of observation is the inheritance. See footnote 22 of the

text.

The figures are based on the present value of all inheritances as of the survey year which were received up to the time of the survey and accumulated at a real interest rate of 3.0 percent for recipients only.

a. In 1984, race is for family and is taken from 1972 interview. In other years, it is the race of the head.

b. Families are classified according to the age of the head of the family.

c. Families are classified according to the education of the head of the family, which is missing for some families. 


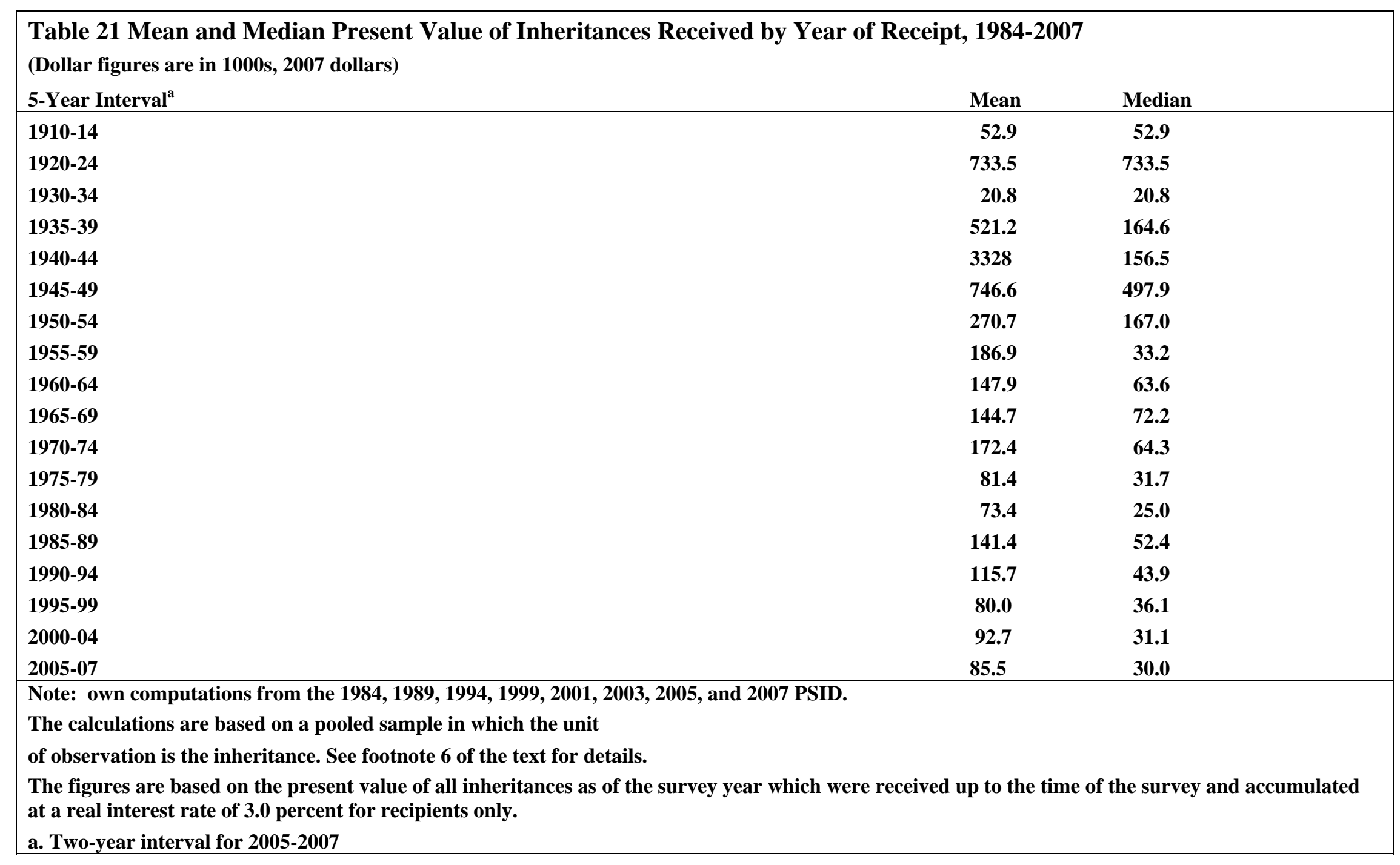




\begin{tabular}{|c|c|c|c|c|c|c|c|c|}
\hline \multicolumn{9}{|c|}{$\begin{array}{l}\text { Table } 22 \text { Inequality of Inheritances Received, 1984-2007 } \\
\text { [Gini Coefficients] }\end{array}$} \\
\hline I. All Families & 0.965 & 0.981 & 0.983 & 0.974 & 0.982 & 0.986 & 0.986 & 0.985 \\
\hline II. Recipents Only & 0.791 & 0.644 & 0.684 & 0.626 & 0.585 & 0.660 & 0.663 & 0.645 \\
\hline \multicolumn{9}{|l|}{$\begin{array}{l}\text { A. Income Level } \\
(1998 \$)\end{array}$} \\
\hline Under $\$ 25,000$ & 0.731 & 0.440 & 0.452 & 0.689 & 0.598 & 0.415 & 0.759 & 0.411 \\
\hline$\$ 25,000-\$ 74,999$ & 0.831 & 0.602 & 0.682 & 0.577 & 0.537 & 0.653 & 0.618 & 0.680 \\
\hline$\$ 75,000-\$ 99,999$ & 0.664 & 0.716 & 0.632 & 0.626 & 0.570 & 0.613 & 0.661 & 0.667 \\
\hline$\$ 100,000-\$ 249,999$ & 0.632 & 0.662 & 0.778 & 0.592 & 0.618 & 0.669 & 0.602 & 0.674 \\
\hline$\$ 250,000$ or more & 0.367 & 0.637 & 0.528 & 0.242 & 0.464 & 0.183 & 0.392 & 0.280 \\
\hline \multicolumn{9}{|l|}{ B. Race ${ }^{\mathrm{d}}$} \\
\hline White & 0.793 & 0.644 & 0.685 & 0.630 & 0.591 & 0.664 & 0.665 & 0.648 \\
\hline African American & 0.638 & 0.380 & 0.408 & 0.374 & 0.340 & 0.314 & 0.327 & 0.486 \\
\hline \multicolumn{9}{|l|}{ C. Age Class ${ }^{\mathrm{e}}$} \\
\hline Under 35 & 0.701 & 0.559 & 0.556 & 0.796 & 0.637 & 0.509 & 0.647 & 0.582 \\
\hline $35-44$ & 0.677 & 0.685 & 0.564 & 0.596 & 0.572 & 0.667 & 0.627 & 0.673 \\
\hline $45-54$ & 0.714 & 0.606 & 0.478 & 0.606 & 0.570 & 0.660 & 0.555 & 0.574 \\
\hline $55-64$ & 0.756 & 0.639 & 0.718 & 0.516 & 0.510 & 0.625 & 0.599 & 0.670 \\
\hline $65-74$ & 0.659 & 0.570 & 0.813 & 0.494 & 0.451 & 0.500 & 0.549 & 0.459 \\
\hline 75 \& over & 0.880 & 0.439 & 0.703 & 0.505 & 0.664 & 0.477 & 0.702 & 0.585 \\
\hline
\end{tabular}




\begin{tabular}{|c|c|c|c|c|c|c|c|c|}
\hline \multicolumn{9}{|l|}{$\underline{\text { D. Education }}^{\mathrm{f}}$} \\
\hline Less than 12 years & 0.698 & 0.485 & 0.484 & 0.775 & 0.424 & 0.754 & 0.310 & 0.524 \\
\hline 12 years & 0.707 & 0.474 & 0.717 & 0.604 & 0.544 & 0.630 & 0.605 & 0.577 \\
\hline 13-15 years & 0.663 & 0.682 & 0.562 & 0.541 & 0.566 & 0.582 & 0.608 & 0.609 \\
\hline 16 years of more & 0.845 & 0.672 & 0.720 & 0.578 & 0.585 & 0.622 & 0.694 & 0.700 \\
\hline $\begin{array}{l}\text { Note: own computa } \\
\text { The figures are base } \\
\text { a. Retrospective per } \\
\text { b. Retrospective per } \\
\text { c. Retrospective per } \\
\text { d. In 1984, race is fo } \\
\text { e. Families are class } \\
\text { f. Families are classi } \\
\text { missing for some far }\end{array}$ & $\begin{array}{l}\text { om the } \\
\text { e prese } \\
\text { omplet } \\
\text { ive year } \\
\text { wo year } \\
\text { y and is } \\
\text { cording }\end{array}$ & $\begin{array}{l}1989,1 \\
\text { lue of al } \\
\text { there is } \\
\text { minim } \\
\text { minim } \\
n \text { from } \\
\text { le age of }\end{array}$ & $\begin{array}{l}\text { 1999, } 20 \\
\text { eritance } \\
\text { inimum } \\
\text { heritan } \\
\text { heritan } \\
\text { intervie } \\
\text { head of }\end{array}$ & $\begin{array}{l}003,20 \\
\text { f the su } \\
\text { eritance } \\
\$ 10,000 \\
\$ 10,000 \\
\text { other } \\
\text { Imily }\end{array}$ & $\begin{array}{l}\text { nd } 200 \\
\text { year }\end{array}$ & $\begin{array}{l}\text { SID. } \\
\text { ch wer }\end{array}$ & eceived & \\
\hline
\end{tabular}




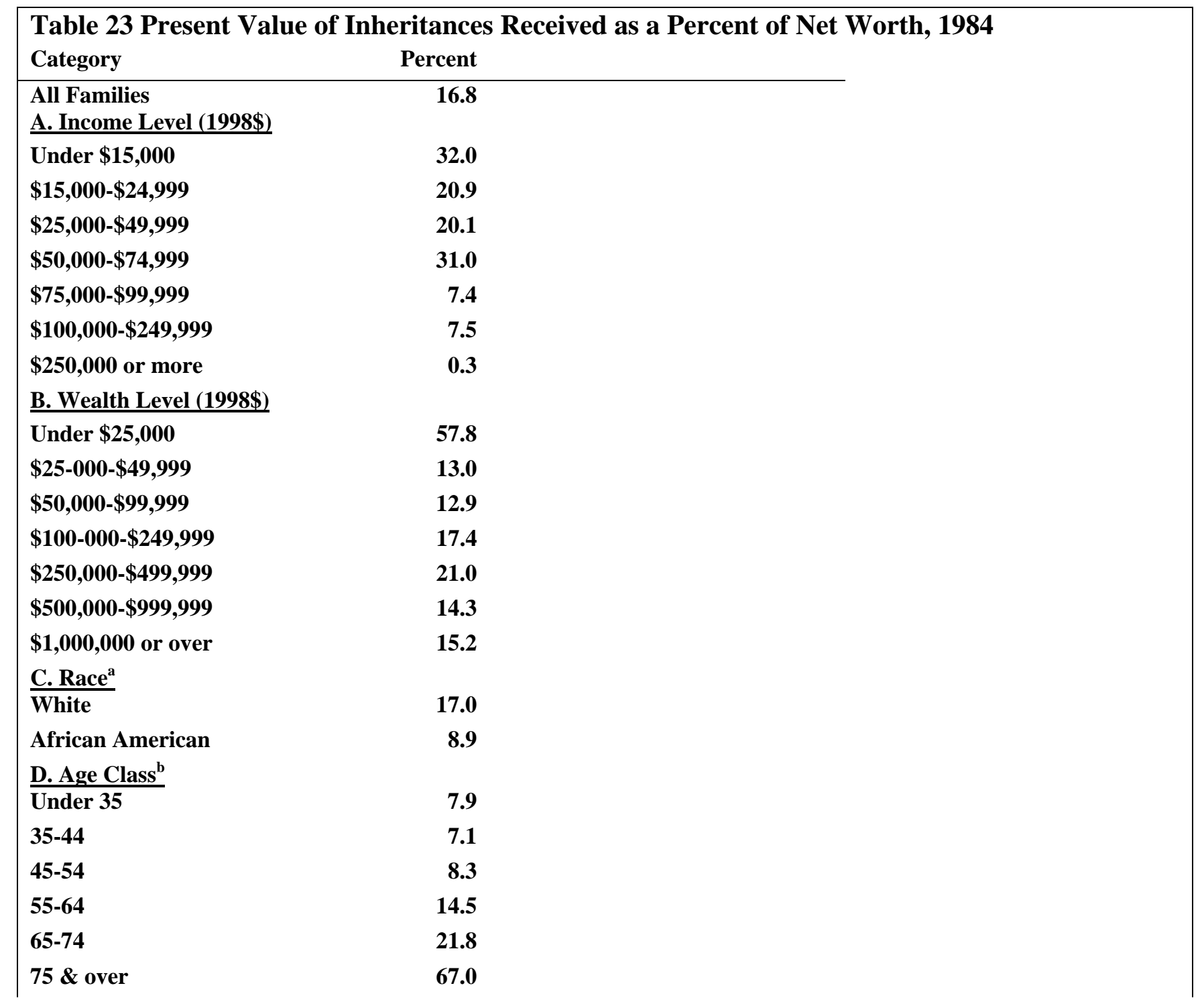


E. Education

Less than 12 years

12 years

13-15 years

16 years of more

Note: own computations from the 1984 PSID.

The figures show the present value of all inheritances as of the survey year which were

received up to the time of the survey and accumulated at a real interest rate of 3.0 percent as a ratio to net worth.

a. In 1984, race is for family and is taken from 1972 interview. In other years, it is the race of the head.

b. Families are classified according to the age of the head of the family

c. Families are classified according to the education of the head of the family, which is

missing for some families. 


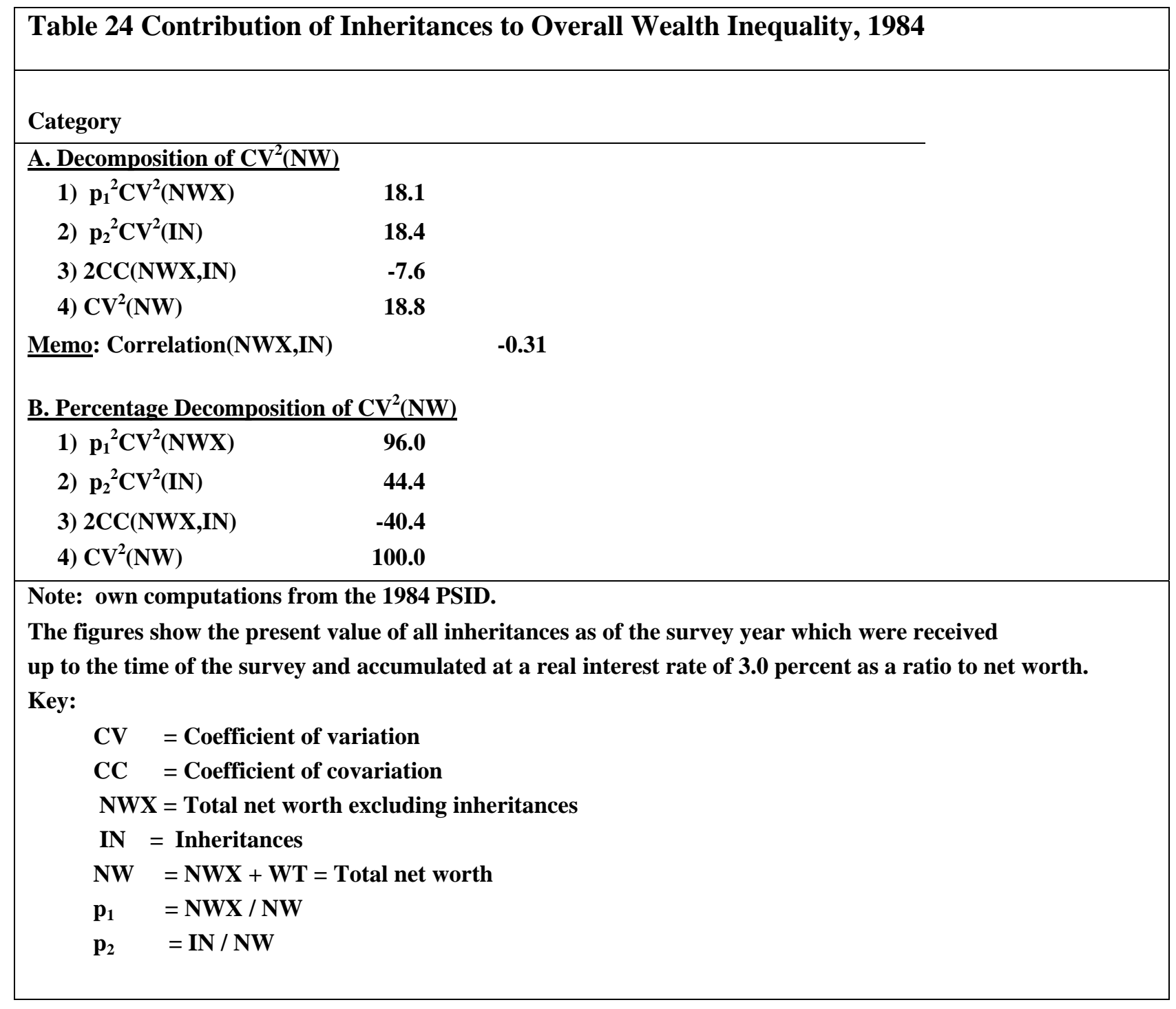


